\title{
A perspectiva ecológica em psicologia
}

LUIS SOCZKA *

"-Would you tell me, please, which may $x$ ought to go from here?

- That depends a good deal on where you want to get to, said the Cat.

-I don't much care where, said Alice.

- Then is doesn't matter which way you go, said the Cat.

-... so long as $I$ get somewhere, Alice added as an explanation.

- Oh, you're sure to do that, said the Cat, if you only walk long enough.»

L. CARroll, Alice in Wonderland

\section{CONDIÇÕES DA PSICOLOGIA \\ AMBIENTAL: A EMERGENCIA \\ DE UMA DISCIPLINA \\ DE EMERGENCIA}

Os historiadores das ciências e das técnicas têm demonstrado de múltiplas formas as relações existentes entre o aparecimento e desenvolvimento daquelas e as condições sociais, culturais, políticas e económicas que as enquadram, entravam ou favorecem.

Assim, é natural que, com u fenómeno nuvo na história dos homens que é a crise ecológica generalizada que hoje vivemos, se desenvolvessem novos campos de pesquisa e de intervenção como resposta à multiplicidade de problemas graves levantados pelas consequências de um desenvolvimento industrial desenfreado, um gigantismo dos centros urbanos, uma concentra-

* Laboratório Nacional de Engenharia Civil, Lisboa. ̧̧ão dos capitais e dos meios técnicos, um crescimento exponencial das populações, um esgotamento acelerado dos recursos naturais não renováveis, uma perturbação profunda dos ecossistemas através das várias formas de poluição ambiental e do desgaste das áreas verdes do planeta e dos solos aráveis.

É no contexto desta crise, que se fez sentir sobretudo a partir dos anos 60 , que particularmente nos Estados Unidos se desenvolve uma disciplina designada psicologia ambiental (environmental psychology). Jovem disciplina, caracterizadamente «comprometida» na linha do projecto global de action research de um dos seus precursores, Kurt Lewin, a psicologia ambiental procura ainda a sua identidade teórica na teia de uma interdisciplinaridade a que é levada não só por uma vaga questão de vocação mas sobretudo pela necessidade premente de se encontrar uma resposta prática para uma das mais dramáticas situações do itinerário histórico da humanidade, que os vários relatórios técnicos produzidos nas duas últimas décadas se encarregaram de divulgar amplamente, numa tentativa de alertar o grande público (o relatório Meadows do M.I.T., o Blueprint for Survival dos ecologistas ingleses, o movimento ecológico e as obras de René Dumont, os relatórios do Clube de Roma e tantos outros).

Mas uma disciplina científica não é um accionismo praticista, e se, como Lewin ousou pro- 
clamar no reino dos empiristas, «nada há de tão prático como uma boa teoria», é urgente que os eco-psicólogos busquem a sua identidade teórica ou, se se quiser e como propôs Studer (1969), o seu paradigma, no sentido de Kuhn (1962).

Importa para tal analisar as suas raízes na história da psicologia, e ver em que ponto da complexa e controversa caminhada temporal dos modelos teóricos, sistemas e atitudes dos psicólogos se começa a propor a perspectiva ecológica, como atitude molar e integrativa, como via de progresso do conhecimento e de eficácia da intervenção; pois se soubermos de onde vem a psicologia ambiental talvez seja mais fácil prevermos para onde ela se dirige. $\mathrm{E}$, dado que decididamente a atitude dos eco-psicólogos é molar (porque molar é a sua problemática), interessa ver sumariamente em que consiste a antítese dessa atitude, característica do behaviorismo e do associacionismo clássicos, de que forma nasce a ultrapassagem teórica das suas limitações e por que vias essa ultrapassagem se encontra ligada à génese da psicologia ambiental.

\section{O BEIIAVIORISMO CLÁSSICO}

\section{E O ASSOCIACIONISMO:}

\section{A ATITUDE MOLECULAR}

O behaviorismo é um sistema (ou seja, um conjunto coerente, organizado e inclusivo de proposições teóricas) que se desenvolveu extraordinariamente nos Estados Unidos a partir do início deste século, com a obra controversa de J. B. Watson $(1914,1919,1925)$. A carreira de Watson (1878-1958) deu origem ao que ficou conhecido na história da psicologia sob a designaçăo de «revolução comportamentalista» e consiste fundamentalmente na insistência numa metodologia objectivista caracterizada pela negação do sujeito como objecto de conhecimento científico e dos dados da introspeçãa como fonte válida de informação, sendo defendido que só os observáveis comportamentais o são, a partir de quatro técnicas: a observação sistemática, com ou sem controlo instrumental, as técnicas reflexológicas, as técnicas dos relató- rios verbais e os testes (Watson, 1919). O objectivo do programa behaviorista era explícito: "Given the stimulus, to be able to predict the response, and given the response to be able to predict the antecedent stimulus.» Daí a formula geral $\mathrm{S} \rightarrow \mathrm{R}$ que designa, nas suas variantes, o modelo behaviorista em psicologia.

O objectivismo watsoniano repousava em vários antecedentes teóricos: a) em primeiro lugar, na tradição da psicologia animal e no evolucionismo darwiniano que postulava um continuum entre as espécies e o emprego de métodos de descrição sistemática e empírica dos comportamentos observáveis, que no início da década de 30 do século XX, incorporados no quadro teórico do darwinismo, dariam origem à escola objectivista da etologia alemã (Konrad Lorenz e continuadores). Nas suas formulações mais rigorosas, e contrapondo-se à tendência descritiva assistemática de Romanes (1886), os zoocomportamentalistas du século XIX reagiam contra o antropomorfismo e o subjectivismo no estudo dos comportamentos, e dessa atitude foi paradigma o famoso cânone de Llọd Morgan (1899): «In no case we may interpret an action as the outcome of the exercise of a higher psychical faculty, if it can be interpreted as the outcome of the exercise of one which stands lower in the psychological scale.» Este cânone, conhe. cido como o princípio da parcimónia, já enunciado outrora por Guilherme de Occam, constitui um apelo à busca das unidades comportamentais simples cujo encadeamento poderia dar origem à elaboração de comportamentos complexos; b) em segundo lugar, no conexionismo de Thorndike (1874-1949), que se radica nas correntes filosóficas empiristas associacionistas. $\mathrm{O}$ ponto de partida do empirismo associacionista era claro: o conhecimento vem-nos das experiências sensoriais (empirismo) e as ideias complexas são construídas a partir da associação de ideias mais simples radicadas nas sensações. Esta tradição de que os filósofos Locke e Hobbes, no século XVII, Hume, no século XVIII, são os principais representantes modernos, impregnou profundamente as culturas anglo-saxónicas, e no século XIX encontrou desenvolvi- 
mento nas obras radicais dos filósofos ingleses James Mill e John Stuart Mill, que desenvolveram teorias mecanicistas dos processos mentais. As expressões científicas destas posições teórica foram dadas sobretudo a partir das obras de Thorndike, na Universidade de Colúmbia, nos trabalhos da escola reflexológica russa de Pavlov e Bechterev, e de Ebbinghaus, na Alemanha. Experimentalista de laboratório que recorria amplamente a sujeitos animais nos seus trabalhos, Thorndike é o grande descritor dos princípios fundamentais dos processos de aprendizagem: através da conexão (ou associação) de aprendizagens elementares (por ensaio-e-erro e obedecendo às leis do efeito e do exercício) constituem-se os comportamentos complexos; c) em terceiro lugar, o reflexologismo russo, de que a principal figura é indubitavelmente o fisiologista Ivan Pavlov (1849-1936). Tendo estabelecido com rigor que é possível, a partir de uma resposta incondicionada a um estímulo incondicionado e através da associação deste a um estímulo condicionado, dar origem a uma nova forma de resposta condicionada, Pavlov formulou com precisão as leis que regem a aquisição e extinção dessas respostas condicionadas, a sua generalização e associação de forma a dar origem a condicionamentos de ordem superior. O método pavloviano assentava assim no experimentalismo objectivista e partia dos puros observáveis comportamentais, constituindo uma radical aplicação do cânone de Morgan.

Em todos estes precursores do sistema behaviorista de Watson encontramos portanto características comuns: a) a recusa do "mentalismo» e a substituição dos funcionamentos psíquicos «interiores» pelos observáveis comportamentais, como objecto de estudo; b) a adopção de um ponto de vista empirista e associacionista, com aplicação do princípio da parcimónia; $c$ ) a exigência de aplicação da metodologia das ciências exactas e naturais aos problemas do comportamento e a recusa dos dados da vivência subjectiva como objecto de estudo; d) a insistência nos factores ambientais como determinantes centrais dos processos comportamentais observados (recusa do inatismo, insistência nas contingên- cias do processo $\mathrm{S} \rightarrow \mathrm{R}$ e na aprendizagem); e) centração prática em hipóteses verificáveis através de um controlo experimental rigoroso, e no estudo de unidades comportamentais simples (molecularismo) com vista a estabelecer as bases da compreensão das unidades mais complexas, por hipótese daquelas derivadas. O molecularismo, não sendo uma exigência intrínseca do modelo $S \rightarrow R$, de facto caracterizou durante décadas os trabalhos dos principais behavioristas; f) atitude determinista, partindo do pressuposto de que todos os comportamentos estão sujeitos a causas determinantes. $O$ objectivo das ciências do comportamento é, assim, pôr em evidência as leis que regem as relações imediatas causa-efeito nas condutas animais e humanas, sendo todas as respostas moldadas pelas suas contingências exteriores, e os comportamentos globais produto das conexões (encadeamentos) de comportamentos elementares.

Ora, afirmou-se acima que a psicologia ambiental tende a ser sobretudo uma psicologia molar (por antítese ao molecularismo); importa ver, portanto, de que forma nasce a oposição a essa atitude característica do behaviorismo clássico (dizemos «clássico», pois há que ressalvar posições teóricas excepcionais, como a de Tolman) e como foram reformulados os pontos centrais desse sistema, particularmente através do desenvolvimento da psicologia da forma (Gestaltpsychologie) e das suas extensões psico-sociológicas.

\section{A GESTALTPSYCHOLOGIE E KURT LEWIN: A ATITUDE MOLAR}

Contrariamente ao behaviorismo americano *, a psicologia da forma, ou gestaltpsychologie, desenvolve-se sobretudo na Europa (Alemanha)

* Dizemos americano porque foi neste país que teve lugar o principal movimento comportamentalista o o que maior impacte teve nos desenvolvimentos ulteriores da psicologia científica. Mas, de facto, existiu também um comportamentalismo europeu, anterior até ao de Watson: o do francês Henri Piéron, cuja influência se limitou praticamente ao seu país natal e cujo papel como precursor do behaviorismo é vulgarmente ignorado pelos psicólogos anglo-saxónicos. 
e radica na tradição fenomenológica de Brentano e Hursserl. A expressão «psicologia da forma» deriva da palavra alemã gestalt, que globalmente se poderia traduzir por «forma», «figura» ou «configuração», mas o conteúdo da palavra original é bastante mais rico do que a sua tradução latina. Citando um dos fundadores do gestaltismo, W. Köhler (1929): «Hoje na língua alemã - pelo menos desde a época de Göethe - a palavra gestalt tem dois sentidos: além do significado de forma como atributo das coisas, tem o de identidade concreta per se que tem, ou pode ter, uma forma como uma das suas características». O que significa que a gestalt é uma realidade irredutível, indecomponível em elementos singulares, cuja análise permitiria compreender a forma na sua totalidade. A posição anti-analítica e anti-molecular do gestaltismo está portanto patente na própria expressão que designa este sistema e anuncia a sua posição epistemologicamente divergente em relação ao behaviorismo. Historicamente, pode afirmar-se que o gestaltismo tem início em 1910, com os trabalhos experimentais de Max Wertheimer sobre a percepção do movimento aparente. Os métodos analíticos, quer wundtianos quer behavioristas, não davam resposta satisfatória para problemas como os levantados pelo fenómeno do movimento aparente (de que o cinema é o exemplo mais evidente), ou a constâncias das formas perceptivas. Dois dos mais proeminentes precursores oitocentistas do gestaltismo, o físico Ernst Mach (1838-1936) e o psicólogo C. Von Ehrenfels (1859-1932) haviam já posto em questão o empirismo associacionista tradicional, afirmando a existência de sensações independentes das propriedades isoladas dos componentes singulares do objecto percepcionado. Num artigo intitulado Sobre a qualidade das formas estruturais («Über Gestaltqualitäten», Viert. fur wiss. Phil., 1890), Ehrenfels distinguiu as «qualidades sensíveis» e as «qualidades formais» dos objectos; no caso de uma melodia, por exemplo, as notas isoladas e sucessivas constituem as qualidades sensíveis da melodia. Mas só a sua sucessão num ritmo suficientemente rápido permite apreciar o seu efeito de conjunto, a sua forma global, as suas Gestaltqualitäten. A percepção do padrão não depende de uma mera soma das propriedades dos componentes isolados; como afirma o aforismo gestaltista: $O$ todo é mais do que a soma das partes.

Ora Wertheimer estava justamente nesta linha de pesquisa, se bem que não imediatamente influenciado pela obra de Ehrenfels, cujos trabalhos passaram relativamente desapercebidos $\mathrm{e}$ foram aliás «recuperados» a posteriori pelo movimento gestalista (cf. Köhler, 1929; Hartman, 1935). Max Wertheimer verificou que se projectasse uma luz sobre dois segmentos de recta, um vertical e outro num ângulo de $30^{\circ}$ em relação ao primeiro, numa sucessão rápida (intervalos de 60 milisegundos) se obtinha a sensação de movimento aparente. Com um intervalo de 200 milisegundos, as posições sucediam-se sem ilusão de movimento, e com um intervalo de 30 milisegundos ambos os segmentos de recta iluminados apareciam, em simultâneo. Este fenómeno de movimento aparente (ou fenómeno Ф) não encontrava explicação nos modelos teóricos wundtianos e behavioristas, e não poderia ser explicado através da análise das propriedades isoladas dos estímulos componentes. Tratava-se de um fenómeno perceptivo irredutível à decomposição analítica em elementos simples — uma gestalt, uma forma estrutural. Obviamente, o mérito de Max Wertheimer não consiste na descoberta do movimento aparente, suficientemente conhecido já em 1910, mas na proposta de uma explicação original para o fenómeno. A sua famosa monografia, publicada em 1912 («Experimentelle Studien über das Sehen von Bewegung», Zeits. für Psych., vol. 60 ), é composta por perto de uma centena de páginas que revolucionaram a psicologia contemporânea justamente devido à riqueza, consistência interna e originalidade do modelo explicativo proposto para o fenómeno $\Phi$. Com excepção do método experimental e da observação sistemática, todos os axiomas da psicologia dominante da época foram abandonados e postos em questão pelo pequeno grupo de defensores radicais da teoria da gestalt que secundava 
Wertheimer, sobretudo Kofka e Köhler, os jovens Dozenten que the haviam servido de sujeitos para as suas primeiras experiências sobre o fenómeno $\Phi$. A proposta gestaltista era de uma tremenda simplicidade, mas as suas consequências revelaram-se muito vastas, pelo cheque em que colocava as correntes associacionistas, analíticas e objectivistas, quer pela sua teoria das formas estruturais irredutiveis e dos mecanismos isomórficos da percepção, quer pela reabilitação que fazia da experiência vivida e do lugar do sujeito na psicologia, de que só praticamente a psicanálise e certos sectores da psicologia clínica faziam a defesa. Foi sobretudo fundamental a questão das totalidades estruturais e da sua indecomponibilidade: assim, as experiências perceptivas surgem como configurações molares ou holísticas; não como uma mera soma de sensações isoladas, mas como totalidades significativas que transcendem as proprie- dades singulares dos seus componentes. Interessa pois estudar os campos de significação, imediatos para o sujeito, o todo dominando as partes e assumindo significações globais irredutíveis. Surge desta maneira a noção de campo psicológico, como representação subjectiva do real, por oposição ao campo físico, objecto específico das ciências da natureza. Tomemos um exemplo, originalmente publicado por Boring, Longfeld e Weld (1948) e retomado por Chaplin e Krawiec (1974): na figura 1 temos nitidamente a sensação de uma espiral. Este efeito de espiral pertence ao campo psicológico do observador, dado que a espiral é efectivamente inexistente. Se seguirmos a curva a partir do ponto $A$, ignorando o efeito global da figura, vemos que regressamos a $A$ : a «espiral» é na realidade constituída por círculos concêntricos. A realidade física do objecto percepcionado, o campo físico, difere assim da sua representação subjectiva,

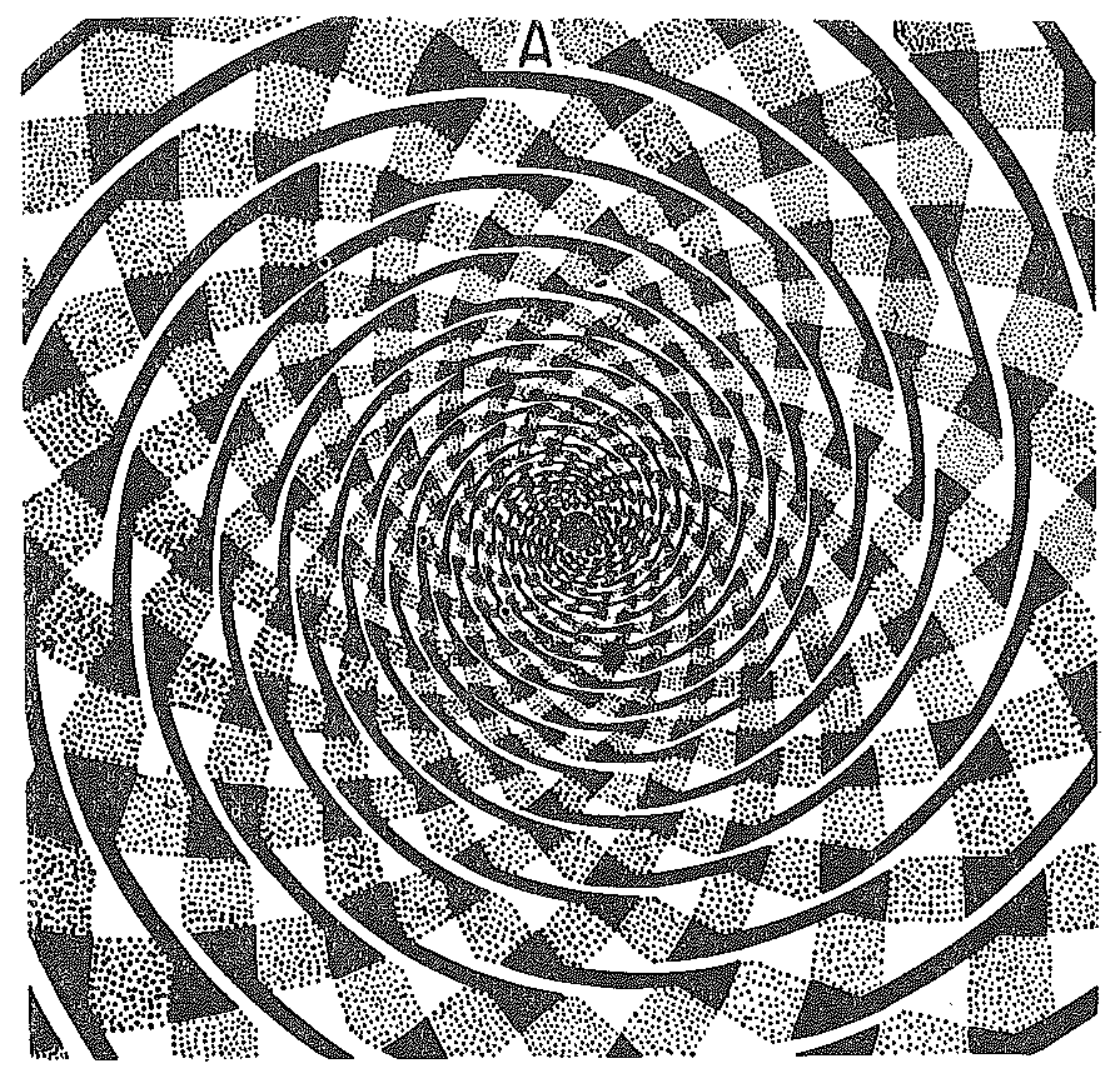

Figura 1

- Ver texto - 
pertencente ao campo psicológico e obedecendo a leis próprias que os gestaltistas [particularmente Wertheimer (1923), Köhler (1929) e Kofka (1935)] enunciaram a partir de trabalhos experimentais que permitiram a formulação de princípios gerais da organização perceptiva no seu entender estruturais e enquadradas pela lei geral do isomorfismo psicofisiológico, assumindo uma atitude crítica em relação ao método analítico e ao molecularismo dos behavioristas, que acusaram de ser um «reducionismo atomista», e não negando o recurso à experiência subjectiva (ao vivido) e aos seus conteúdos fenomenológicos-que os comportamentalistas americanos haviam proscrito radicalmente da psicologia como contrários ao paradigma científico que defendiam.

Se Wertheimer, Kofka e Köhler se debruçaram particularmente sobre a problemática das organizações perceptivas, numa primeira fase do movimento gestaltista coube sobretudo ao alemão Kurt Lewin (1890-1947) a transposição dos princípios da Gestaltpsychologie para o campo da personalidade, dos comportamentos sociais e da psicologia da criança, e sobretudo para o campo da intervenção social (action research).

Lewin iniciou a sua carreira integrado na escola de Berlim, e aí produziu (até à sua partida para os Estados Unidos devido às perseguições nazis) trabalhos experimentais sobre a vontade, a memória e os hábitos, e particularmente sobre os sistemas de tensão, na linha dos trabalhos anteriores de Ach (1910), tema desenvolvido pela discípula de Lewin, Zeigarnik (1928), que verificara o incremento da persistência em situações de interrupção de tarefas programadas (efeito Zeigarnik). Após a emigração para os Estados Unidos, em 1932, Lewin desenvolve as suas teorias topológicas do com" portamento e da personalidade, primeiro na Universidade de Stanford e Cornell e na Universidade de Iowa (1935) e finalmente no M.I.T. (1944). O terceiro período da carreira de Lewin, o mais curto mas certamente não o menos fecundo, caracteriza-se por um maior investimento nos problemas de psicologia social aplicada, particularmente a dinâmica grupal, e por um maior interesse pelas questões levantadas pela influência do meio (social e não-social) nos comportamentos colectivos, surgindo então a proposta de desenvolvimento de uma ecologia psicológica, que Lewin infelizmente não teve ocasião de aprofundar antes da sua morte, em 1947.

Se é verdade que a Gestaltpsychologie não conseguiu compatibilizar-se com o behaviorismo americano, quer devido às dificuldades imediatas de linguagem (os trabalhos fundamentais de Wertheimer, Kofka e Köhler haviam sido publicados em alemão) quer devido às próprias dificuldades conceptuais e ao antagonismo de atitudes, princípios e métodos entre gestaltistas e behavioristas, é também certo que Lewin, de todos os psicólogos alemães no exílio, foi aquele que mais brilhantemente se impôs à admiração dos americanos, quer pela fecundidade das suas hipóteses e dos seus modelos teóricos quer pela elegância e inteligência dos seus trabalhos experimentais. Como o afirmam Marx e Hillix (1974): «the lines of work started by Lewin cer. tainly did not stop with his death. He was one of those rare individuals who are in tune with the times twenty-five to fifty years after they are no longer alive (...) To say that Kurt Lewin was one of the germinal figures for modern psychology is praise too faint.»

Vejamos então alguns dos pontos mais salientes do sistema teórico desenvolvido por Kurt Lewin.

a) Modelo «aristotélico» e modelo «galileicon: dois modos de pensamento em conflito

Em 1931, Lewin publicou no Journal of General Psychology um artigo intitulado «The conflict between Aristotelian and Galileian modes of thought in contemporary psychology», que ainda constitui um precioso documento teórico sobre o estatuto epistemológico e a metodologia da psicologia.

A lógica aristotélica é classificativa, isto é: procede por agrupamento abstracto dos carac- 
teres dos objectos singulares de forma a definir conjuntos correspondentes à intersecção dos conjuntos que definem a totalidade dos caracteres desses mesmos objectos (a classe). A lei correspondendo à noção de produção sem excepção de uma classe de eventos, ou à sua produção tão frequente que se pode afirmar a regularidade legal com um enorme grau de certeza. $O$ evento singular está assim afastado enquanto objecto de conhecimento científico, dado que releva da aleatoridade e por definição escapa à regularidade. $\hat{\mathrm{E}}$ portanto indeterminado. Só a classe, abstractamente definida, enquanto conjunto das propriedades comuns a todos os eventos ou objectos considerados, enquanto correspondência lógica à natureza essencial desses objectos, é passível de determinação, logo de legalidade ou regularidade. A estabilidade de ocorrência de um evento é portanto critério para o estabelecimento da lei, expressão formal da regularidade absoluta dessa ocorrência. Daí a incompatibilidade entre o individual (ou singular) e a determinação, objecto do conhecimento científico.

Em psicologia, esta atitude traduz-se pela recusa do caso individual como objecto de ciência (e daqui decorre a recusa behaviorista do dado subjectivo e do método directo para o alcançar, a introspecção) e a insistência nas regularidades estatísticas como via de formulação das leis do comportamento, confirmação de hipótese ou até de simples intelegibilidade dos fenómenos. A lógica das classes é a regra de jogo universal em zoologia, em botânica, em física. $\mathrm{Na}$ medicina, onde a vemos dominar «o nascimento da clínica»: «O que a medicina classificatória chama histórias particulares são os efeitos de multiplicação provocados pelas variações qualitativas (devidas aos temperamentos) das qualidades essenciais que caracterizam as doenças. $O$ indivíduo doente encontra-se no ponto em que aparece o resultado dessa multiplicação. Dai o paradoxo: quem desejar conhecer a doenca deve subtrair o individuo com as suas qualidades singulares» (Foucault, 1963). A classificação surge, inerentemente, como um objectivo fundamental da psicologia, com o risco conhe- cido de circularidade explicativa: «Actualmente, a psicologia da criança e a psicologia da afectividade ilustram claramente o hábito aristotélico de considerar as classes abstractamente definidas como a natureza essencial do objecto particular e portanto como uma explicação do seu comportamento. Tudo o que as crianças da mesma idade têm em comum torna-se o carácter fundamental dessa idade. Assim, o facto de as crianças de três anos apresentarem quase sempre uma atitude negativa é considerado como a prova de que o negativismo é inerente à natureza da criança de três anos $e$ o conceito de idade ou de estado negativista é então considerado coma uma cxplicação ainda que sem dúvida incompleta - para o aparecimento de uma atitude negativa num dado caso particular» (Lewin, 1931). Desta atitude surge-nos como paradigma a perspectiva de A. Gesell, em psicologia do desenvolvimento, por exemplo, mas hoje, como na época em que Lewin escrevia o seu artigo, ela é de facto a mais comum entre os psicólogos e preside às divergências de perspectivas entre os experimentalistas e os clíni$\cos$, que D. Lagache (1947) denunciou como obstáculos (não de fundo mas práticos) a uma real unidade da psicologia.

Ora o que Lewin põe em questão não é tanto o recurso a critérios de natureza estatística mas o seu modo de utilização e sobretudo o seu emprego como substitutos de uma outra ordem conceptual, própria do ponto de vista ou modo de pensar "galileico», e daquilo que designou por método «construtivo». Com Galileu, Kepler e Newton a física começou a libertar-se da tradição aristotélica e elevou-se a uma ordem superior de abstracção independente da lógica classificativa e do empirismo descritivo que atć então a caracterizavam. É assim que a queda dos graves deixa de ser um fenómeno isolado «explicável» pelo «horror ao vácuo» para passar a ser um fenómeno da mesma ordem e obedecendo à mesma lei universal que rege a órbita dos planetas e o movimento pendular. O Universo torna-se então homogéneo e não mais dividido em classes que seriam a expressão de diversas essências, cada qual com as suas pro- 
priedades distintas. A quantificação é posta ao serviço da compreensão do particular e do concreto, e não apenas utilizada para a etiquetagem estatística de fenómenos cuja estrutura interna permanece por compreender e explicar: a lei não é uma média aritmética. $O$ individual deixa de pertencer ao puro aleatório e encontra-se tão determinado como o que é estatisticamente regular, torna-se objecto de estudo científico e de intelegibilidade.

Com o abandono da lógica classificativa e descritiva, verifica-se igualmente $o$ abandono da visão estática do Universo. Ê precisamente a dinâmica, estranha ao pensamento aristotélico (para o qual os corpos se encontravam «naturalmente» em repouso), o que vai permitir uma outra possibilidade de penetrar na natureza de um fenómeno, uma outra maneira de dar conta dos traços específicos dos casos particulares (Lewin, 1931). Enquanto que na física aristotélica os fenómenos são determinados pela própria natureza, pela essência dos objectos, na física contemporânea pensa-se em termos de interacçóes de vectores físicos e nas relações entre as propriedades do objecto $e$ as do seu meio. Abandona-se assim a perspectiva «intrinsecalista» dos fenómenos, e a ênfase é colocada nas relações de forças existentes num dado campo físico. A totalidade da situação-eis o que é necessário compreender para explicar a dinâmica da relação entre o objecto e o seu ambiente. A situação concreta na sua totalidade e singularidade torna-se não só objecto do conhecimento científico como a sua compreensão se revela essencial para esse mesmo conhecimento: «Consequentemente, o que importa hoje para o estudo da dinâmica não é abstrair da situação, mas procurar minuciosamente as situações em que as variáveis estratégicas da estrutura dinâmica total podem ser discernidas mais clara, distinta $e$ puramente - não nos referimos já à média abstracta do maior número possível de casos historicamente dados, mas ao carácter total concreto das situaçôes particulares») (Lewin, 1931).

Reconhecemos aqui a defesa dos princípios da Gestalt: a dominância das estruturas ou for- mas globais sobre as partes componentes, o apelo para a compreensibilidade do concreto e do singular. Em 1935, nos seus Principles of Topological Psychology, Kurt Lewin retomou a mesma questão: «The application of laws pressupposes the comprehension of individual cases. One can apply a law only if one knows the nature of the concrete case with which one is dealing. Considered from this point of view, the laws are nothing more than principles according to which the actual event may be derived from the dynamic factors of the concret situations (p. 11). À totalidade em questão deu Lewin o nome de campo psicológico ou espaço de vida (Life space), nele incluindo a pessoa $(\mathrm{P})$ e o seu ambiente (E), e sendo portanto o comportamento função da interacção dinâmica entre ambos: $\mathrm{B}=\mathrm{f}(\mathrm{P}, \mathrm{E})$. No desenvolvimento deste conceito, Lewin concluirá mais tarde que a psicologia deverá tornar-se o estudo da ecologia particular dos indivíduos ou dos grupos.

b) A noção de campo psicológico ou espaço de vida

Ao recorrer à noção de campo, Lewin procede tão somente a uma analogia metateórica com o conceito de campo da física moderna.

A física aristotélica preocupou-se com os objectos em si mesmo considerados, numa perspectiva estática, tendo por fim conhecer a sua essência. Com Galileu e Newton nasce uma nova física, onde os conceitos dinâmicos ocupam o primeiro plano e onde já não se buscam essências mas relações matemáticas: é o início do fim da tradição aristotélica nas ciências físicas e renasce de certo modo a perspectiva de Arquimedes. Para Galileu a natureza é matemática (cf. Opere di Galileo Galilei, Florença, 1890, vol. I., cit. Lenoble, 1966). Desenvolveu-se a partir de Maxwell a noção de campo; assim, no caso de dois corpos, como a Terra e a Lua, assume-se que existe tal interacção entre ambos que a estrutura do espaço em seu redor é modificada pelo conjunto das forças criadas pela copresença desses dois objectos materiais. As relações entre essas forças podem 
ser descritas através de equações de campo, sendo cada campo particular caracterizado por um determinado conjunto de equações diferenciais parciais. $\hat{E}$ portanto o campo de forças como estrutura global que deve ser objecto de estudo e não cada um dos objectos componentes, em si mesmo considerado, dada a interacção permanente entre todas as forças co-presentes. Deste modo, a teoria de campo é sobretudo um método de análise e uma matriz particular de hipóteses teóricas globais, uma outra forma de olhar as relações entre o objecto e o seu meio envolvente: mais do que uma teoria é uma constru ção metateórica de ordem superior, que contém em si teorias regionais ou parcelares.

Ora é justamente na Alemanha contemporânea dos grandes nomes da física moderna (os quais gozavam já de um prestígio público quase mítico: o Kaiser Wilhelm Institüt de Berlim incluía, nos anos dez, figuras como Max Planck, Walther Nernst, Gustav Hertz, Albert Einstein, Erwin Schrödinger) que os gestaltistas (entre os quais Lewin) desenvolvem as suas experiências e o seu modelo teórico. Não admira portanto que o ambiente fosse favorável ao impacte da «nova física» sobre os «novos psicólogos», nomeadamente através da assimilação metateórica e analógica da teoria do campo e das novas perspectivas da causalidade introduzidas pela teoria einsteineana da relatividade. $\hat{\mathrm{E}}$ no entanto necessário ter em conta que só por remota analogia é possível a transposição do conceito de campo da física para a psicologia, e vários foram os cientistas (entre os quais Robert Oppenheimer) que puseram reservas à sua aplicação psicológica.

Já vimos sumariamente a distinção gestaltista etnre campo físico e campo psicológico, este último bastante ligado à ideia de experiência fenomenal mas ultrapassando o subjectivismo fenomenológico na medida em que os gestaltistas souberam impor uma metodologia experimental aos seus trabalhos e, embora valorizando o dado vivido, não deixaram de proclamar a sua comunicabilidade e a sua observabilidade, e pressupõem a não equação entre o real e o mundo fenomenal.
Para Lewin, é fundamental essa distinção, e podemos dizer que o eixo daquilo a que podemos chamar o «sistema lewiniano» é a noção de espaça de vida. Em 1935, Lewin define o real como «aquilo que produz efeitos» (Lewin, 1935, p. 19). O campo psicológico é portanto o conjunto das variáveis que influem no comportamento do indivíduo num dado tempo $t$ (princípio da contemporaneidade, que veremos adiante), englobando o subsistema pessoal e o subsistema ambiental, e a zona fronteiriça que sapara as variáveis psicológicas das não-psicológicas. O campo psicológico é assim definido pela parcela do real que existe para o sujeito. Note-se que Lewin não identifica a experiência fenomenal com o seu conceito de espaço de vida: define-o não em termos de cognição do real mas em termos de efeitos reais. Trata-se, portanto, de um constructo de base comportamentalista e não puramente fenomenológico. Notełse também que não se trata de um modelo cognitivista: Lewin admite que há causas conscientes e inconscientes susceptíveis de produzir efeitos comportamentais. Mas é clara a distinção entre o campo físico «objectivo» e o campo psicológico: «We don't have to include within the psychological life space the whole physical world with his objective characteristics in terms of physics. The facts are to be included in the representation of the psychological life space only on the extent and in the manner in which they affect the individual in his momen tary state. We express this by calling them quasi-physical facts» (Lewin, 1935, p. 24). Analogamente, podem considerar -se os factos quase-sociais, ou seja aqueles de entre os factos sociais realmente existentes que de uma forma ou de outra afectam o comportamento do sujeito num dado tempo $t$. Note-se ainda que a noção de sujeito pode ser aplicada quer ao indivíduo quer ao grupo.

Uma das teses centrais da teoria do campo é o chamado princípio da contemporaneidade a que acima fizemos referência. A teoria do campo admite logicamente que o jogo de forças num dado camp.o está em permanente mudança, e introduz uma alteração importante na pers- 
pectiva clássica da continuidade espaço-tempo: é o campo num tempo $t$ que é objecto de conhecimento. A mudança num ponto $x$ do campo físico num tempo $t\left(\frac{\mathrm{dx}}{\mathrm{d} t}\right)$ é função apenas $\mathrm{da}$ situação nesse tempo $\left(\mathrm{S}_{\mathrm{t}}\right)$ e como objecto é independente das situações $S_{t+n}$ ou $S_{t-n}$ : pressupor por exemplo a acção de $S_{t-1}\left(\right.$ ou $S_{t+1}$ ) no campo em $t$, é possível apenas quando se conhece a relação condicional entre $S_{t-1}$ (ou $S_{t+1}$ ) e S. É portanto teoricamente possível es. crever $\frac{d x}{d t}=f\left(S_{t+n}\right)$ ou $\frac{d x}{d t}=f\left(S_{t-n}\right)$. Mas só no caso de serem conhecidas as leis que condicionam a relação entre $S_{t}$ e $S_{t-n}$ ou $S_{t+n}$; caso as leis da mudança nos sejam desconhecidas aquelas equações não possuem significado algum. O que a teoria do campo psicológico afirma é que, na medida em que só nos interessam, de entre os eventos da situação $S_{t-\ldots}$, aqueles que influem actualmente em $S_{t}$, o objecto de análise é o comportamento em $t$ como função do campo englobante do sujeito e do seu ambiente. Lewin tem todavia o cuidado de precisar que o tempo $t$ «não se refere a um momento sem extensão no tempo, mas a um determinado período de tempon (Lewin, 1943; cf. Lewin, 1951), dependendo a extensão desse intervalo do objectivo em vista. Evidentemente, Lewin aceita que tanto o passado psicológico de um sujeito (ou de grupo) como o seu futuro podem influir na situação presente - mas não como niveis de realidades e sim como representações actuais desse passado e desse futuro.

E assim que a expectativa de um sujeito ou o seu nível de aspiração em relação a um objectivo ainda não alcançado pode influenciar o comportamento no tempo $t$. Mas justamente na medida em que é já uma variável actuante no campo psicológico do sujeito, pertence à situação actual, ao espaço de vida do sujeito, é portanto componente de $S_{\mathrm{t}}$ : é então possível aceitar uma função $B_{f}=t_{(S t+n)}$. Mas só na medida em que se conhccem as leis que regem essa função, neste caso exemplar as do nível de aspiração do sujeito - o que Lewin efectiva* . mente fez, ao determinar experimentalmente
(Lewin, Dembo, Festinger e Sears, 1944) que o nível de dificuldade (V) é igual ao produto da valência do sucesso $\left(V_{\text {su }}\right)$ pela probabilidade subjectiva de sucesso ( $\mathrm{PS}_{\mathrm{su}}$ ) menos o produto da valência do fracasso $\left(V_{f}\right)$ pela probabilidade subjectiva de fracasso $\left(\mathrm{SP}_{\mathrm{f}}\right): \mathrm{V}=\left(\mathrm{V}_{\mathrm{su}} \mathrm{SP}_{\mathrm{su}}\right)$ $-\left(\mathrm{V}_{\mathrm{f}} \mathrm{SP}_{\mathrm{f}}\right)$; de notar que Lewin introduz aqui um modelo probabilístico no seu método de análise, e que essa reclamação fora apresentada justamente por um dos seus críticos (Brunswick, 1943), ele mesmo defensor dos modelos probabilísticos em psicologia, mas também de uma perspectiva diacrónica aparentemente minimizada por Lewin. Para analisar a dinâmica do campo psicológico Lewin recorre a constructos oriundos da física: tal como um campo físico se define por forças caracterizadas por componentes de intensidade e direccionalidade, também Lewin recorre a expressões como «sistemas de tensão», «vectores», «valências», "campo de forças», «fluidez», "conflito de forças», «barreiras», etc., que procuram traduzir a dinâmica da situação. Fiel ao seu ponto de partida epistemológico, Lewin não se contenta em recorrer aos constructos como entidades nominais explicativas (o que seria recair no criticado modo de pensamento aristotélico), mas preocupa-se em estabelecer relações dinâmicas e, tanto quanto possível, em apresentar propostas para a sua formalização. É disso paradigma o quadro I, onde Kurt Lewin analisou os constructos aplicáveis aos trabalhos que Zeigarnik realizou sob a sua orientação entre 1924 e 1926 (recorde-se que a lei de Zeigarnik estabelece que a grandeza de força psicológica em relação à memorização de uma actividade é uma função positiva da grandeza da tensão psicológica intrapessoal associada a essa mesma actividade).

Ao contrário de alguns outros grandes nomes na história da psicologia, Lewin teve um grande cuidado em evitar aquilo que Bachelard (1970) designou pelo «obstáculo substancialista». A noção de obstáculo epistemológico corresponde ao facto de, no caminho histórico do conhecimento científico, se verificarem arraigamentos 
a conceitos pseudo-explicativos funcionando como «tranquilizantes» cognitivos que entravam, por vezes duramente, o progresso desse mesmo conhecimento. Não nos deteremos aqui na análise (erradamente denominada «psicanálise» pelo autor) magistral a que Bachelard submete esta questão dos obstáculos epistemológicos, e o seu lugar na génese do pensamento científico contemporâneo, particularmente nos séculos XVII e XVIII. Bastar-nos-ia referir, para o nosso propósito, a denúncia bachelardiana de um tipo particular de obstáculo: o substancialismo, correspondente à atitude atributiva de propriedades substanciais aos fenómenos ime-

\section{QUADRO I}

SUMÁRIO E VERIFICAÇÃO DE ALGUMAS CONSTRUÇŌES, HIPÓTESES E DERIVAÇÕES DE ZEIGARNIK

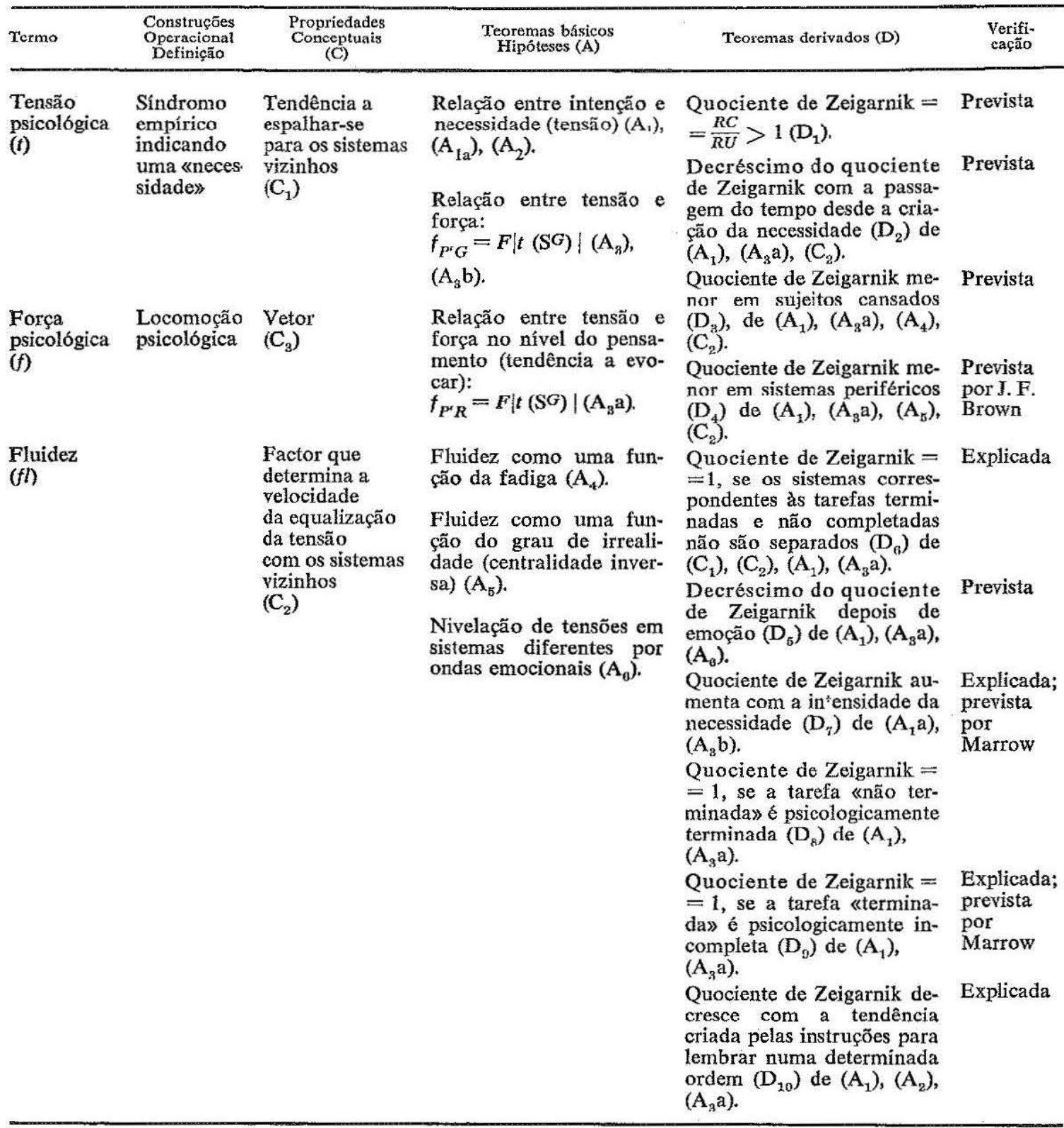


diatos, de molde a «abafar» todas as perguntas subsequentes. A palavra qualificativa substitui-se tranquilamente à análise, e o real é encerrado na circularidade do discurso nominalista: é assim que para o físico Aldini (Essai théorique et experimental sur le galvanisme, 1804) «a substância da electricidade fica impregnada pelas substâncias que atravessa»; para Priestley (Histoire de l'électricité, 1771) «o corpo eléctrico lança uma emanação glutinosa que se apodera dos corpúsculos que encontra no seu caminho e os traz consigo no seu regresso ao corpo de onde partes; e para Carra (Nouveaux principes de physique, 1787) o magnetismo é produto de «uma fleuma que sai do imã». Se estes exemplos falam por si, mais difíceis de denunciar são os que tocam a uma jovem ciência como a psicologia: mas não será esse o obstáculo epistemológico a ultrapassar quando um Freud nos fala de energia libidinal, quando um McDougall nos fala de energia instintual ou um Lorenz. de energia específica de acção?

Em Lewin não encontramos nenhum vestígio de substancialismo, mas a análise da dinâmica das relações. Tomemos o exemplo, extraído de Lewin (1938), de uma situação simples: uma criança que se vê confrontada com o problema de comer um alimento que the desagrada. Um caso portanto de conflito entre o seu desejo (não ingerir esses alimentos que considera desagradáveis) e a perspectiva de enfrentar os adultos que the dizem para ingerir esses alimentos. Lewin representa a situação de acordo com os esquemas da figura 2.

O espaço de vida é representado como um campo de forças finito, integrando regiões macroscópicas: a criança (C); comer os alimentos (Re); colocar as mãos na mesa (h); pegar na colher (Sp); colocar comida na colher (fo); erguer a colher e apontá-la à boca (hw); levar a colher à boca (m); meter a comida na boca (i); mastigar (ch); engolir (Sw); lutar ou enfrentar os adultos (St); a liberdade da criança (Fr); a força dirigida para a liberdade (fC, Fr); a força de evitamento da luta (fC, - St). Comer possui uma valência negativa $[\mathrm{Va}(\mathrm{Re})<0]$ e fc,--Rc aumenta na razão inversa da distância entre
$\mathrm{C}$ e Re. Se a criança comer realmente os alimentos, verifica-se uma alteração na direcção das forças, dada a fuga ao confronto com os adultos (b); (c) representa uma estádio posterior: a situação é reestruturada, e (m) passa a ser representado como uma subregião de Re. Uma força psicológica é portanto mensurável através da intensidade das forças opostas, a persistência relativa da actividade orientada e a velocidade de locomoção ou reestrututuração do campo. Não encontramos aqui as «virtudes atractivas» próprias dos papagaios «eléctricos» de Dubois (Tableau annuel de la

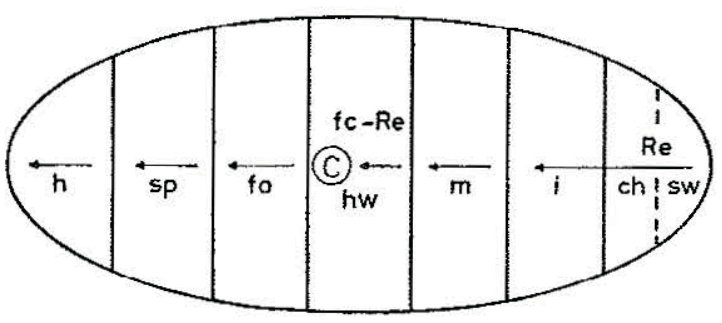

(a)

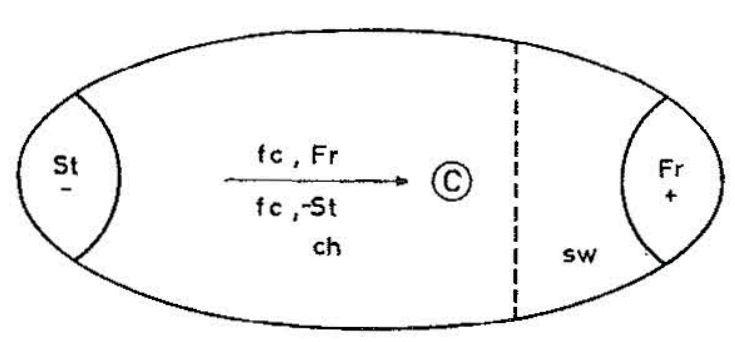

(b)

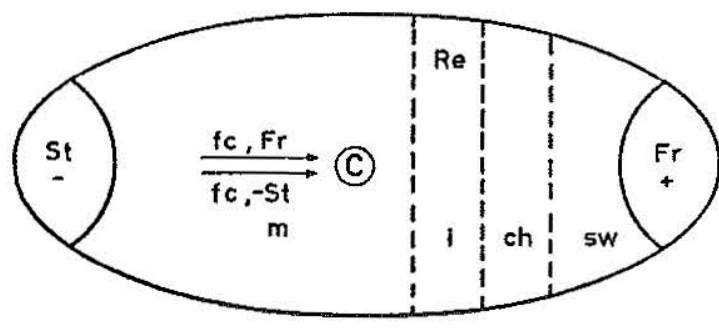

(c)

Figura 2 
Physique, 1772) mas apenas sistemas de tensão que fundam a análise da vertente emocional dos processos psicológicos, desde os processos de decisão à dinâmica dos grupos restritos. As propriedades do campo não são propriedades substanciais: são um sistema de relações matematicamente traduziveis, logicamente formalizáveis; sem nunca se cair todavia num outro obstáculo epistemológico, este ainda em voga - a numerologia: "O excesso da precisão no reino da quantidade corresponde muito precisamente ao excesso de pitoresco no reino da qualidade. A precisão numérica é frequentemente uma sublevação dos algarismos, tal como o pitoresco, é, para falar como Baudelaire, uma sublevação dos pormenores») (Bachelard, 1970, p. 213).

\section{c) Campo de grupo, campo social \\ e ecologia do comportamento}

Referimos acima que no último (e mais curto) período da sua carreira (1938-47) Lewin dedicou-se sobretudo ao estudo da dinâmica dos grupos e aos problemas de psicologia social. No entender de alguns comentadores (Faucheux, 1959; Cornaton, 1979), Lewin morreu justamente quando ia encetar um quarto período da sua trajectória científica: a passagem do estudo dos grupos (que de si representava já um deslocamento do campo individual para a problemática dos campos colectivos) para o estudo dos meios sociais onde os grupos se inserem.

No seu estudo dos grupos (da "dinâmica» dos grupos, conforme a expressão que utiliza a partir de 1944), Lewin aplica o aparelho teórico anteriormente desenvolvido por ele e por outros gestaltistas.

Os grupos são assim considerados como gestalten, campos de forças particulares definidos por objectivos, normas e valores próprios, formas de organização, redes de interacções e comunicações, determinações peculiares (totalidades dinâmicas, em suma) irredutíveis a uma análise dos indivíduos que compõem os grupos. Seria despropositado enveredar aqui por uma exposição dos trabalhos de Lewin sobre a dinâ- mica dos grupos, até às suas experiências finais sobre os «T-group»: nem os objectivos deste artigo nem o espaço o consentiriam, dada a envergadura desses trabalhos. Mas é importante frisar a noção de campo aplicada a situações colectivas e mais concretamente a passagem final de Lewin à noção de campo social, dada a sua relevância teórica e prática. Efectivamente, «após ter estudado o campo do grupo $K$. Lewin aborda os problemas do campo social onde a intervenção psicossociológica nas estruturas reais assume o lugar da experimentação em laboratório» (M. Tavares da Silva, 1977). Na última fase da sua carreira, Lewin envereda pela abordagen da ccologia social dos grupos, ou seja: alarga a noção de campo às variáveis sociológicas que atravessam e influenciam o grupo como realidade social: «A representação do grupo e do seu ambiente como um campo social é um instrumento básico para a análise da vida do grupo. Isto significa que a ocorrência social é vista como acontecendo e resultando da totalidade das entidades sociais co-existentes, como grupos, subgrupos, membros, barreiras, canais de comunicação, etc. Uma das características fundamentais desse campo é a posição relativa das entidades que são partes do campo. Esta posição relativa representa a estrutura do grupo $e$ o seu ambiente ecológico. Expressa também as possibilidades básicas de locomoção dentro do campo. $O$ que ocorre dentro desse campo depende da distribuição de forças em todo o campo. Uma previsão pressupõe a capacidade de determinar a intensidade e a duração das forças resultantes para os vários pontos do campo. De acordo com a teoria geral do campo a solução de um problema de vida do grupo tem que se basear num procedimento analitico desse tipo. Só considerando os grupos em questão no seu ambiente real podemos assegurar que nenhuma conduta essencial possivel foi descuidada» (Lewin, 1947). Neste artigo final, Lewin aborda os processos sociais como estados quase-estacionários e apresenta um modelo formal para o tratamento analítico dos equilíbrios quase-estacionários na vida dos grupos, enqua- 
drados nos seus contextos sociais reais, mas infelizmente não the foi já possível desenvolver esta linha de pesquisas tardiamente encetada.

Foi certamente importante para a abertura de Lewin a esta perspectiva ecológica «alarga$d a »$, as críticas que lhe foram dirigidas, nomeadamente por Egon Brunswik (1943), de ter desenvolvido um sistema fechado, «pós-perceptual e pré-comportamental». Em resposta a Brunswik, Lewin (1943) distingue três áreas relevantes para a psicologia: 1) o espaço de vida, 2) os processos físicos e sociais que naquele momento não afectam o espaço de vida e 3) uma «zona limítrofe» do espaço de vida, constituída pelos processos físicos e sociais «que afcctam o estado do espaço de vida naquele momento». Brunswik acusa Lewin de «encapsulação» ao ignorar as variáveis ambientais (físicas e sociais) que não pertencem ao campo psicológico tal como é definido no sistema lewineano. Embora recuse que um evento físico com uma certa probabilidade objectiva de ocorrência (um terramoto, por exemplo) mas que não afecta o comportamento do sujeito (porque este ignora subjectivamente essa probabilidade) num dado tempo $t$, possa ser considerado parte do campo psicológico do sujeito nesse tempo: $t$, Lewin aponta uma via de abertura: «Posso compreender porque é que a Psicologia se deveria interessar por aquelas áreas do mundo físico $e$ social que não são partes do espaço de vida ou não afectam no momento a sua zona limítrofe. Se se deseja salvaguardar a educação de uma criança durante os próximos anos, se se deseja prever em que situação um indivíduo se encontrará a si mesmo como resultado de uma determinada acção, deve-se calcular esse futuro. Obviamente, essa antevisão tem que ser parcialmente baseada em considerações estatisticas de dados não psicológicos. Teoricamente, podemos caracterizar essa tarefa como a de descobrir que partes do mundo físico e social determinarão a zona limítrofe do espaço de vida durante um certo tempo. Esta tarefa é digna do interesse do psicólogo. Sugiro denominá-la ecologia psicológica» (Lewin, 1943). Note-se que Egon Brunswik era engenheiro de formação inicial, e mes- mo durante o período posterior em que estudara psicologia na Universidade de Viena recebera grande influência dos positivistas lógicos do Circulo de Viena. Após o seu doutoramento com Bühler, em 1927, fora professor de matemática e física em Viena, antes de Tolman o chamar para Berkeley. Não é admirar, por" tanto, que acusasse o sistema de Lewin de cair num «subjectivismo encapsulado» por aparentemente ignorar as condições físicas e sociais do ambiente objectivo - para Brunswik, que é ele próprio considerado um «field theorist» (Marx e Hillix, 1974), é fundamental controlar as variáveis ambientais reais, parametrizar os seus valores e analisar as suas interacções, sem o que a caracterização da situação total se torna impraticável e não há previsão possível do comportamento.

Mas não foram apenas as críticas de Brunswik que conduziram Lewin à «ecologia psicológica». Em 1943 vivia-se nos Estados Unidos a guerra. Um dos problemas sociais práticos envolvia o problema da alimentação e dos hábitos de alimentação e da resistência à mudança desses hábitos. Não é de estranhar, portanto, que tenha sido esta questão a despoletar o primeiro grande trabalho de alargamento da teoria de campo à ecologia do comportamento - é fundamental recordar que Lewin se caracterizou por um grande amor ao concreto e uma grande atenção ao quotidiano, e é lícito pensar que a fecundidade da psicologia depende justamente dessa atitude. É assim que em 1943 Lewin publica (Bull. Nat. Thes. Connect., 108:35-65) um artigo intitulado «Forces behind food habits and methods of change», mais tarde refundido e publicado em Field theory in Social Science sob o título sugestivo de "Psychological ecology». Nesse trabalho Lewin analisa sistematicamente, em resposta à pergunta «porque é que as pessoas comem o que comem?», os canais de acesso dos alimentos à mesa onde são consumi* dos, e as decisões intermediárias que presidem à sua selecção. É evidente que uma pergunta de semelhante envergadura levou o seu autor a ultrapassar necessariamente o quadro de uma análise psicológica e a defrontar-se com variá- 
veis sociológicas, políticas, económicas, ambientais que alargaram a teoria do campo à problemática dos envolventes físicos e sociais do espaço de vida.

Por essa mesma linha enveredaram dois dos seus discípulos mais brilhantes e talvez por isso mesmo mais críticos: H. F. Wright e Roger G. Barker.

\section{OS PRIMÓRDIOS DA PSICOLOGIA ECOLÓGICA: BARKER E WRIGHT}

Cartwright (1959) analisou criticamente as concepções lewinianas de espaço de vida e as críticas de Brunswik, apresentando aí uma sugestão para a ultrapassagem das dificuldades conceptuais envolvidas no modelo de Kurt Lewin. O modelo lewiniano é esquematicamente representado da seguinte forma:

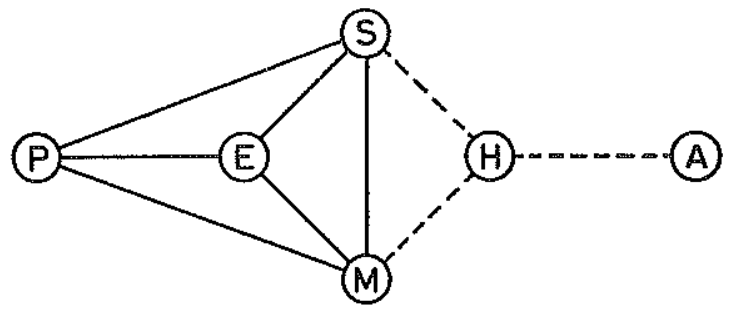

Fig. 3-(Cartwright, 1959)

onde $P$ representa o sujeito, $E$ o ambiente psicológico, $S$ o sensório (ou seja: a zona fronteiriça do espaço de vida que recebe a informação ou estimulação do mundo físico-social), $M \circ$ motório (ou seja, a zona igualmente fronteiriça do espaço de vida que age sobre o mundo físico-social), $H$ a envolvente ( $h u l l$ ) exterior do espaço de vida ( $«$ Those facts that are not subject to psychological laws but which influence the state of the life spaces, Lewin, 1936) e $A$ os restantes factos do mundo físico-social que não têm influência no espaço de vida do sujeito num dado tempo $t$. Cartwright inclui no espaço de vida $S$ e $M$, que são por seu turno afectados por $H$. As experiências de Cartwright e Festinger (1943), sobre os tempos de decisão, estabeleceram que quando sujeitos adequadamente preparados são confrontados com um determinado par de estímulos com um dado grau de similaridade, se produz uma tal constelação de forças no ambiente que o tempo requerido para a resolução das forças em conflito depende da natureza dessa constelação e não ocorre uma decisão observável até que esse conflito tenha sido resolvido. A expressão matemática desta teoria envolve a especificação de constantes (o tempo de reacção básico do sujeito, que é propriedade do sistema $H-S-M$ ) e a transformação de um «tempo psicológico» (propriedade do sistema $E-P$ ) num «tempo físico» (propriedade de $H$ ). Assim, o que ocorre no espaço de vida é função de um sistema global $[P, E, S, M, H]$. A descrição e análise de $H$ é necessária, com evidência, e o psicólogo não pode dar-se ao luxo de a desprezar. Brunswik preocupara-se já, aliás, com a solução de compromisso perceptual (o índice de razão de Brunswik, unitário em condições de constância perfeitas) que permite a estabilidade entre as dimensões distais e proximais das representações, o que envolve a caracterização exacta da natureza dos objectos físicos ou $H$, no esquema de Cartwright). Ora foi essa justamente a perspectiva de Barker e Wright no seu monumental estudo da ecologia comportamental de uma pequena cidade do Kansas, a partir de 1947, e que constituiu o primeiro trabalho de eco-psicologia de grande envergadura.

R. G. Barker cedo se associou a Lewin: em 1932, durante a estadia de K. Lewin na Universidade de Stanford, tendo então nascido um dos mais fundamentais estudos laboratoriais sobre a frustração e a regressão, utilizando crianças como sujeitos (Barker, Dembo e Lewin, 1941). $\mathrm{E}$ foi precisamente no domínio do comportamento infantil (da ecologia do comportamento infantil) que Barker, em colaboração com H. F. Wright, produziu o seu trabalho pioneiro de ecologia psicológica (Barker e Wright, 1955). Na sua obra de síntese, Ecological Psychology (1968), Barker explicita as características desse estudo: «The environment is seen to consist of highly structured, improbable arrangements of objects and events which coerce behavior in accordance with their own dynamic patterning. 


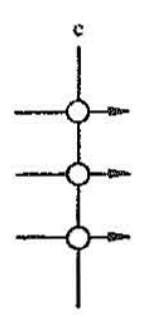

Passado remoto do organismo

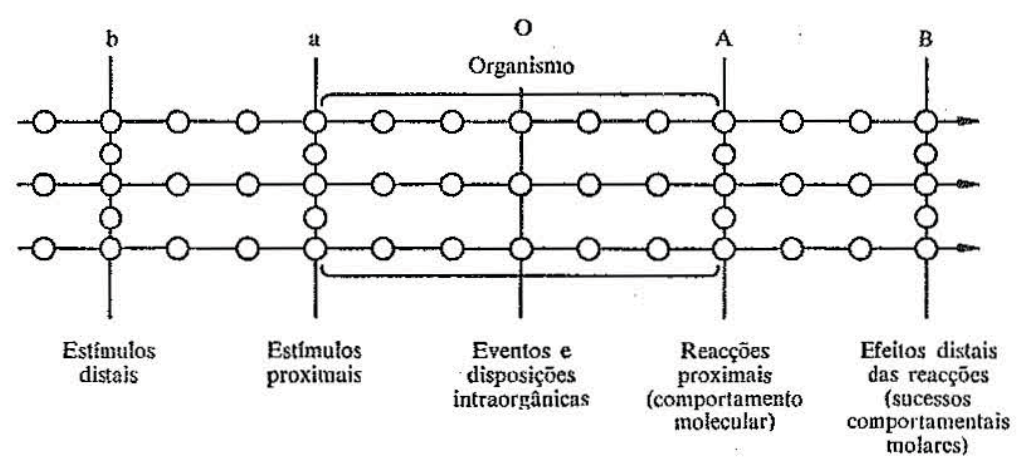

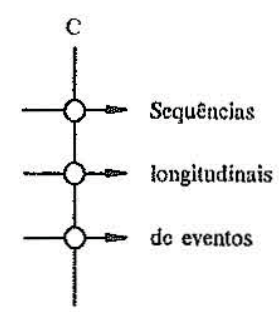

Sucessos

longínquos,

produlos das actividade
vitais

Fig. 4-(Brunswik, 1939; extraído de Marx e Hillix, 1974)

When early in our work at the Field Station, we made long records of children's behavior in real-life settings in accordance with a traditional person-centered approach, we found that some attributes of behavior varied less across children within settings than within settings within the days of children. We found, in short, that we could predict some aspects of children's behavior more adequately from knowledge of the behavior characteristics of the drugstores, arith metic classes and basketball games they inhabited than from knowledge of the behavior tendencies of particular childrens. Desta forma, Barker viu-se confrontado à necessidade prática de caracterizar os meios físicos e de escapar ao perigo de «encapsulação» para que Brunswik alertara Lewin.

É aliás notável a influência de Egon Brunswik nos escritos teóricos e na perspectiva de Barker (Barker, 1963, 1965, 1968), que recorre ao conceito de circuito ambiental (environmental circuit) desenvolvido por Brunswik. Na figura 4 reproduz-se o esquema apresentado por Brunswik para representar o seu modelo conceptual.

Para Brunswik, o organismo $(O)$ e os eventos actuais pertencem a uma cadeia temporal ordenada sistematicamente em «camadas» de variáveis, desde as experiências remotas (c) até aos estímulos físicos distais $(b)$, os estímulos proximais (a) que influem no estado interno de $O$; este, apresenta respostas proximais $(A)-$ comportamento molecular - e projectam-se nos seus produtos a longo prazo $(C)$. Trata-se, portanto, de um circuito ou arco $E-O-E$; os behavioristas ocuparam-se fundamentalmente do circuito $a-$ $-(O)-A$ e os psicanalistas da cadeia $C-O$. $\hat{\mathrm{E}}$ objecto de uma abordagem ecológica dar conta da globalidade do arco E-O-E, numa perspectiva molar. $\mathrm{Na}$ perspectiva lewiniana, insiste-se sobretudo no aspecto intrapessoal do circuito ambiental, e os gestaltistas insistem nas leis psicológicas que presidem à organização interna do input sensorial.

Ora, dada a incomensurabilidade do arco E-O-E, e a infinita multiplicidade dos níveis de análise a que ele pode ser sujeito, há que definir unidades operacionais para o seu estudo. Barker utiliza um método naturalista, recorrendo a técnicas de observação directa não muito distantes dos procedimentos das técnicas de campo dos etologistas europeus. Para tal, o primeiro passo é estabelecer unidades comportamentais compativeis com as possibilidades $\mathrm{e}$ objectivos do investigador. Essas unidades são constructos molares: «O indivíduo não sua ou saliva, nem dobra os joelhos ao andar, nem move a lingua ao falar, ou os olhos quando lê, nem se dobra pela cintura quando se senta. Ele anda, fala, lê ou senta-se, deixando ao cuidado dos seus aparelhos glandulares ou motores a tarefa de suar, salivar, articular, mover $e$ outras unidades comportamentais de que, por serem moleculares, a pessoa não dá conta ao fazer o que faz» (Wright e Barker, 1950). As unidades comportamentais são portanto constructos teóricos, e procede-se à segmentação do continuum comportamental em episódios 
comportamentais não da forma artificial como uma distância pode ser medida em centímetros ou pés, mas atendendo tanto quanto possível à realidade quotidiana: «Behavior episodes (...) are not arbitrarily imposed divisions of the behavior continuum, in the way that microtome slices of tissues and mile-square sections of the earth's surface are imposed divisions. They are, rather, natural units of molar behavior with the attributes of constancy of direction, equal potency throughout their pars and limited size range» (Barker, 1963). A ecologia do comportamento tem por objectivo identificar e descrever essas unidades e esses episódios e relacioná-los com os seus contextos ambientais, com base num modelo teórico integrativo. $\mathrm{O}$ estudo dos padrões comportamentais é feito no meio natural da vida quotidiana dos sujeitos estudados, e não em laboratório - ainda aqui a perspectiva de Barker coincide, portanto, com a atitude da escola etológica europeia, e continua a linha aberta por Lewin no seu último período, como vimos.

Barker e Wright (1955) descrevem esses meios físicos ou cenários comportamentais («behavior settings») a partir de seis grandes categorias ou dimensões: o tempo de ocupação (número total de horas em que o local em questão é ocupado pelos sujeitos durante um periodo de tempo determinado); a penetração (referente à medida do envolvimento e responsabilidade dos ocupantes em relação ao local); os padrões de acção (padrões de comportamento tipicamente associados ao local); os mecanismos comportamentais (aspectos pontuais do comportamento, medidos em termos da sua frequência, duração e intensidade) e a riqueza (medida pela variedade de comportamentos possíveis nesse cenário).

Os autores identificam ainda os cenários em função de um conjunto de propriedades objectivas: a sua visibilidade, o seu carácter fenome. nal (correspondem à experiência comum a toda a gente: a escola, a drogaria, a igreja da paróquia, etc.), a sua dinâmica interna («envolvem as pessoas, o meio psicológico e o comportamento num campo de forças interactuante»), a sua compreensibilidade $(95 \%$ dos comportamentos das crianças de Midwest - nome fictício para a cidadezinha do Kansas onde decorreu o estudo de Barker e Wright - ocorreram nos cenários comportamentais identificados), a sua variedade de atributos e a sua dinâmica externa (ou interdependência dos cenários). Barker e Wright procedem à caracterização pormenorizada e cuidadosa de cada um dos cenários comportamentais, episódios comportamentais, unidades comportamentais e objectos comportamentais (uma boneca, uma escova de dentes, etc.). $O$ estudo de uma grande unidade ecológica, como Midwest, torna-se assim tão pormenorizado e objectivo que parece afastado definitivamente o risco de «encapsulação» da psicologia ecológica apontado por Brunswik. Num artigo posterior, Barker (1963) analisa as propriedades auto-regulatórias dos cenários comportamentais, como extensão do conceito lewiniano de estados sociais quase-estacionários (Lewin, 1947): «The recasting of the eco-behavioral problem does not abandon a first approximation to Kurt Lewin's conception of science: it does not abandon derivations; and the life space remains intact. Within a behavior setting a person contributes to the setting by which he, himself, is constrained. The life space is the means by which the setting secures the behavior appropriate to it. And in this connection, it is important to note that in any self-regulaed system variety within the system is necessary if varied disturbances outside the system are to be countered. This is true of behavior settings, too, diversity of the life space makes possible behavior setting unity and stability. One problem of eco-behavioral science is to investigate how diversity and uniformity on the level of persons contributes to the unity and stability of behavior settings. In the past, important resources of psychology have been committed to the development of vetoing regulators which reduce diversity within settings. There is a great need now to understand how the powerful deviation-countering control mechanism of behavior setting can produce unity and stability in con- 
junction with variety among its inhabitants» (Barker, 1963).

Não entraremos aqui na análise crítica dos critérios que presidiram à selecção das unidades e dos episódios comportamentais nos trabalhos de Barker e Wright. Na obra fundamental de Hutt e Hutt (1970), essa discussão é apresentada com clareza, e o grande mestre da observação naturalista que é sem dúvida alguma Konrad Lorenz, num artigo que curiosamente tem passado despercebido mesmo nos círculos etológicos (Lorenz, 1958), não deixa de chamar a atenção para as organizações gestaltistas da percepção que regem o nosso conhecimento do real, exactamente no sentido em que as regularidades molares identificadas por Barker e Wright são gestalten comportamentais. Há no entanto que ressalvar a distinção, feita por Wright (1967) entre acções, enquanto comportamentos molares (assim as unidades «João saiu de casa» ou «Maria sentou-se no banco do jardims) e os actones, unidades moleculares que são normalmente comuns nas descrições etológicas dos padrões comportamentais (ao proceder ao seu inventário dos comportamentos infantis de modo a contribuir para o repertório etogramático da espécie humana, McGrew (1973) distingue 110 destes actones num total de 10789 observações). O que não impede que os etólogos recorram igualmente ao agrupamento dessas unidades moleculares em unidades molares que são gestalten. Recorremos a essas macro-unidades comportamentais na descrição do comportamento de $M$. fascicularis (Soczka, 1974), observando perto de 12000 interacçốes sociais em 110 horas; assim, o padrão dito «jogo de perseguição», também identificado por McGrew nas crianças, envolve uma pluralidade de micro-unidades que por si só não possuem o significado funcional do padrão global, e até, pelo contrário, pođem associar significados opostos - quer o jogo de perseguição, quer a perseguição agonística, envolvem uma unidade comportamental comum ao início de ambas as sequências ou episódios comportamentais - o «staring». Só o desenrolar total da acção permite distinguir o seu carácter lú- dico ou agonístico, indescernível no início da acção.* Hutt e Hutt (1967) criticam no entanto o subjectivismo patente nas observações de Barker e Wright, por não se limitarem à descrição naturalista objectiva mas procederem à sua interpretação. Efectivamente, encontramos em Wright (1967) registos do tipo: «A relutância de Wally pareceu tornar Ben mais insistente» (p. 174) ou «Mary parecia satisfeita mas encarou o caso com naturalidade» (p. 184). A questão, que é levantada por Hutt e Hutt é, portanto, a de saber até que ponto pode ir a descrição de um comportamento sem perder as características de objectividade a que os etologistas nos habituaram desde os tempos em que se puseram em causa as narrativas antropormórficas do comportamento animal, encontráveis por exemplo no extenso anedotário que é a obra de um Romanes.

Em primeiro lugar, todo o conhecimento é já interpretativo. Toda a percepção é uma construção de um sujeito percepcionante, e não há conhecimento sem atribuição de significado; a própria palavra é interpretativa. E claro que a gestalt que permite a Wright afirmar «Mary parecia satisfeita» pode ser decomponível numa multiplicidade de actones relativos a um conjunto de contracções musculares da face de Mary, à dilatação das suas pupilas, às suas vocalizações e à postura do seu corpo. Mas esses elementos isolados, por rica que seja a sua descrição pormenorizada, não podem ser anteriores à gestalt: Mary parece satisfeita (para uma dis. cussão desta questão, cf. Buytendijk, 1952, 1958; Lorenz, 1958; Ricoeur, 1965).

Num artigo de 1965, Barker levanta outro problema de interesse: o do papel do psicólogo enquanto transdutor ou enquanto operador no sistema por ele analisado. Brunswik (1955) demonstrou que todas as escolas e subdisciplinas da psicologia se ocupam de uma forma ou de

* E aliás notória a dificuldade de distinguir os padrōes agonísticos reais dos padrões lúdicos pseudo. -agonísticos em etologia, o que normalmente só se consegue a partir da identificação de sinais de segunda ordem constituintes de metalinguagens específicas, correspondentes a sofísticadas combinatórias etogramáticas indescerniveis para um observador inexperiente. 
outra de sectores diferenciados do arco E-O-E, como já apontámos acima. Mas nenhuma delas prescinde dos dados primários que lhe vêm da observação da realidade, mesmo quando a posição epistemológica adoptada é hipotético-dedutiva, como em Hull e Lewin - dificilmente se encontrará, na história da psicologia, cientista mais atento ao quotidiano do que Kurt Lewin. O que importa, portanto, é analisar os tipos de relação entre o cientista e os fenómenos que lhe inspiram a pesquisa. Barker (1965) distingue dois grandes tipos de atitudes: a que coloca o psicólogo na posição de transdutor, isto é, de receptor, codificador e transmissor, tanto quanto possível passivo, do input sensorial, como descritor de um real em que procura não intervir; e a que coloca o psicólogo na posição de operador, isto é, o próprio psicólogo intervém no sistema em estudo, controlando as variáveis, influenciando as condições de input da informação, intervindo simultaneamente como transdutor e como agente da situação.

Esta última atitude parece ser a que os modelos dominantes da psicologia adoptaram desde o início do século, e não a via da primeira atitude, o que não significa que a psicologia se tenha caracterizado pela sua intervenção social, dado o carácter artificial e limitado das situações micro-sociais construídas pelos psicólogos de laboratório. $O$ que fez com que, como I. Altman notou (Altman, 1976), dado o contraste entre a atitude de Barker e colaboradores, e a da psicologia social dominante, os seus trabalhos $\mathrm{e}$ os métodos utilizados tenham de certa forma sido menos considerados até há poucos anos. O que, no entender de Altman, se relaciona com a situação de ruptura prática entre os eco-psicólogos emergentes na última década e os psicólogos sociais clássicos. Mas voltaremos adiante a esta questão. Terminaremos esta breve análise do contributo de Barker e colaboradores para o desenvolvimento da psicologia ecológica com uma citação significativa, extraída de Barker (1965): «A central problem of our science is the relation between ecological events (the distal stimuli) at the origin of $E-O-E$ arcs and the succeeding events along these arcs. To solve this problem, psychologists will have to became transducers vis-à-vis the phenomena of psychology. The problem here is not 'what behavior occurs when 1 , as operator, introduce input $\times$ ?' but rather 'what inputs do $I$, as transducer, sense under ecological condition $Y$ ?'. An operator, by undertaking to regulate the input to the psychological phenomena he studies, deprives himself of the possibility of investigating the unregulated input. But there are a number of reasons for avoiding the role of transducer in psychological research: the resulting $T$ data do not fit easily into the hardware, the bureaucracies, the research designs, on the concepts of psychology's establishment which has been shaped by previling operator data-generating systems. The skills and personality attributs required of a successful transducer are different from those of a successful operator, and they are doubtless not congenial to many persons. The techniques of the transducer are in many respects more difficult than those of the operator. And, most important, perhaps, the transducer has less easy access to the organism sector of psychological units, i.e., to psychology's challenging 'black box'.

However, there are grounds for beliewing that despite these reasons for avoiding the transducer role, it will become more important in the years ahead. In relatively uniform and stable environments, people are the source of behavior variance and the dominant scientfic problem concerns the nature of the black box where the secrets of individual differences are stored. (...).

But in varied and changing environments, the contribution of environmental input to the variance of behavior is enhanced. In a restless world, the nature of the environments is the intriguing scientific problem. And the applied fields and neighbouring sciences ask: what are environments like-What programs of inputs do underdeveloped countries, windowless office buildings, and integrated schools provide for people? The questions can only be answered by psychologists functioning as transducers. 
We know which of these worlds we live in today, and it does not seem likely that our own curiosities and the demands of engineers, economists, educators, and political leaders will allow us to be content with a psychology of people to the neglect of a psychology of the environment of people».

\section{OS CAMINHOS DA PSICOLOGIA AMBIENTAL HOJE}

A profecia de Barker realizou-se. Perante as dimensões alarmantes da crise ecológica, uma nova geração de psicólogos viu-se na obrigação de abandonar a torre de marfim dos minuciosos ensaios de laboratório, dos elegantes modelos in vitru, e meter a cabeça no mundo em vez de continuar a tentativa clássica de meter o mundo na cabeça. Começou-se a compreender que, como dizia Edgar Morin (1973), «o homem tem de se considerar o pastor dos nucleoproteinados, os seres vivos, e não o Gengis Khan dos arredores do Sol».

O ímpeto que caracterizou o desabrochar da psicologia ambiental foi de tal ordem que, pouco mais de dez anos volvidos sobre as primeiros sinais de emergência social desta disciplina de ponta, já se torna muito difícil proceder a um balanço pormenorizado da situação actual. $O$ que não é de espantar; outra disciplina do século XX, a etologia, necessitou de quarenta anos de vida para que começassem a surgir as grandes obras de síntese, como os trabalhos monumentais de Hinde (1969) e Wilson (1974). Como estranhar então que a jovem psicologia ambiental careça ainda de uma síntese semelhante que abarque os milhares de trabalhos até hoje realizados?

E no entanto possível detectar grandes linhas de pesquisa que têm sido objecto da psicologia ambiental na última década, e grandes áreas de orientação. Wohlwill (1970), Craik (1973), Altman (1976) publicaram artigos de síntese nesse sentido, e começaram a surgir os manuais dedicados a esta disciplina, embora traduzindo ainda perspectivas parcelares e orientações assás diferenciadas, como as obras de Proshansky, Ittelson e Rivlin (1970), Wohlwill e Carson (1972), Heimstra e McFarling (1974), Mehrabian e Russel 1974), Ittelson, Proshansky, Rivlin e Winkel (1974), Altman (1975), Wagner e Kaplan (1976), Altman e Wohwill (1976), Moore e Golledge (1976), Bell, Fischer e Loomis (1978). Desde 1969 é publicada a revista Environment and Behavior, e desde 1976 Environmental Psychology and Nonverbal Behavior, que juntamnete com Human ecology são os porta-voz das múltiplas pesquisas no domínio da psicologia ambiental. Nos Estados Unidos, as editoras Sage e Plenum Press têm dedicado especial atenção a esta temática. Tudo indica que a psicologia ambiental começa a invadir a Europa, o que não é desanimador se pensarmos que no caso da dinâmica de grupos de Kurt Lewin decorreram perto de quinze anos antes de ser introduzida em França, e que cinquenta anos após o seu desabrochar com os trabalhos pioneiros de Konrad Lorenz e seis anos decorridos desde a atribuição do Nobel aos fundadores da etologia, esta continua praticamente ignorada em Portugal. Que caminhos parecem então destinados a esta disciplina de emergência?

Em primeiro lugar, o facto de, apesar de haver o reconhecimento mais ou menos geral entre os eco-psicólogos do interesse e valor da perspectiva de Wright e Barker, quando mais não seja pelo seu aspecto pioneiro, o modelo barkeriano figura hoje como um dos modelos possíveis em psicologia ambiental, entre outros. A esse modelo particular reservou-se (mais por convenção ou reconhecimento histórico do que por qualquer outra razão, cremos) o nome de psicologia ecológica. E evidente que toda a psicologia ambiental é por definição uma psicologia ecológica. Todavia, nem toda a psicologia ambiental coincide com os modelos e métodos de análise dos discípulos de Lewin e daí o reservar-se a expressão «psicologia ecológica» à linha desenvolvida por Barker e Wright, em particular. A par desta «psicologia ecológica» mais fiel a Lewin, encontramos outras grandes áreas de pesquisa por sinal dominantes na psicologia ambiental contemporânea: 
a) Em primeiro lugar, toda a tradição de interface entre psicólogos, arquitectos, urbanistas e planeadores regionais, a que grosso modo se pode chamar psicologia arquitectural ou urbanística. O seu campo de pesquisa poderia definir-se como o estudo dos impactes psicológicos das formas físicas construídas, apesar de certamente ser esta uma definição ainda um tanto vaga, dado que muitos dos estudos em psicologia arquitectural não incidem só sobre im. pacte das formas físicas construídas mas também variáveis ligadas a estes settings, como os problemas da iluminação, da térmica ambiental, da psicoacústica arquitectural. Trabalhos representativos desta linha de pesquisa estão patentes nas conferências dedicadas à «arquitectural psychology» e realizadas na Europa em 1969, 1971 e 1973, por exemplo (Canter, 1969; Honikman, 1971; Küller, 1973). Ainda em 1973, Bell, Randall e Roeder publicaram uma criteriosa selecção bibliográfica dos principais trabalhos sobre o comportamento humano em meios humanos, entre 1940 e 1972 , e muito da obra clássica de Proshansky et al. (1970) incide no domínio da psicologia arquitectural. A importante conferência, presidida por Canter e Lee (1974), distingue-se das precedentes por ser a primeira organizada directamente por um departamento universitário de psicologia, o que parece ser indicativo de um certo grau de prioridade histórica na solicitação dos arquitectos e urbanistas aos psicólogos. e não do contrário. Disso parece ser testemunho o facto de, já em Março de 1972, o American Institute of Planners ter dedicado um número inteiro do seu Journal ao tema «psicologia e planeamento urbano». Uma rápida análise das origens dos autores dos artigos publicados na principal revista de psicologia ambiental, Environment \& Behavior, revela-nos que grande parte deles são geógrafos, sociólogos urbanos, arquitectos e urbanistas, e que os locais de pertença institucional dos psicólogos implicados nesta área são muitas vezes departamentos universitários de arquitectura, geografia, urbanismo e ecologia e gabinetes técnicos de planeamento regional. Parece mais uma vez significativo que a primeira solicitaçăo de psicologia ambiental em Portugal parta de uma instituição do Ministério da Habitação e Obras Públicas, o LNEC, e que tenha ainda sido no LNEC que se desenvolveu um projecto de pesquisa (pioneiro entre nós) no domínio dos comportamentos urbanos (Valente Pereira, 1970) e outro sobre os factores da incomodidade dorivada da poluição sonora (Martins da Silva, 1975; Martins da Silva e Correia Gago, 1977; Soczka, 1980a, cf. Comissão Nacional do Ambiente, 1980), ainda em curso sob o patrocínio da Secretaria de Estado do Ambiente.

b) Em segundo lugar, e directamente relacionado com a linha de pesquisa da psicologia arquitectural, o domínio da proxémica, a que poderíamos igualmente chamar psico-sociologia da espacialidade.

De todos os subdomínios da psicologia ambiental, a psico-sociologia da espacialidade é a que revela maior influência da etologia, que desde os trabalhos de Howard (1920) tem dedicado especial atenção aos fenómenos de territorialidade, às dimensões espaciais das regulações comportamentais intra e interespecificas $\mathrm{e}$ à sua funcionalidade biológica. Se bem que as problemáticas da disposição espacial, da territorialidade, das densidades populacionais e dos "efeitos de grupo e de massa» tivessem merecido milhares e milhares de páginas de estudos teóricos, experimentais e de campo aos cientistas do comportamento animal (bastará citar a título de exemplo as obras de Grassé (1951), Carpenter (1958), Winne-Edwards (1962), Klopfer (1968), Lorenz (1969), Eibl-Eibesfeldt (1970), Holloway (1974), Wilson (1975) que contêm extensas referências aos materiais publicados pelos etólogos desde os já citados trabalhos de Howard), só recentemente despontou o interesse por fenómenos análogos no campo do comportamento social humano. A influência etológica é nítida em duas obras já clássicas que de alguma maneira constituíram os fundamentos da psico-sociologia da espacialidade: a de Hall (1966) e a de Sommer (1969). Noutros autores, essa influência é menos nítida, e são mais 
claras as reservas à transposição das noções etológicas para o comportamento social humano, como é o caso de Edney (1974) e Altman (1975), que publicaram extensas revisões da literatura sobre este assunto. Altman (1976) distingue áreas dominantes neste campo de estudo: a problemática do espaço pessoal (distâncias interpessoais e suas variações intra e interculturais), a do comportamento territorial (apropriação do espaço e sua defesa) incluindo os temas da marcação personalizada dos espaços e me* canismos sociais de regulação da ocupação do espaço, e a problemática da densidade populacional (tradução imperfeita do conceito de «crowding»). Todos estes problemas, porém, terão sido alvo de uma parte substancial dos trabalhos em psicologia ambiental, como é visível através do facto de aproximadamente $35 \%$ dos artigos publicados nos últimos dez anos na principal revista de eco-psicologia (Environment \& Behavior) se situarem na área da psico-sociologia da espacialidade.

c) A psicologia ambiental percepto-cognitiva. Nesta área poderíamos incluir uma enorme quantidade de estudos que se ligam bastante à psicologia social das representações, e que incidem sobre as modalidades de percepção de formas urbanas, ambientes naturais, comunidades, bairros, ruas, ou particularidades ambientais como um aeroporto, a qualidade da água ou do ar, os ruídos de tráfego, etc. Neste subdomínio incluem-se igualmente os estudos do desenvolvimento das atitudes perante o ambiente, resistência à mudança dessas atitudes, organização ontogenética da percepção do ambiente e da representação do meio físico e suas variações culturais, etc. Bastante recentemente, Moore (1979) publicou uma interessante revisão dos trabalhos publicados neste domínio da «environmental cognition» onde é feito o ponto da situação. Nas suas conclusões, apresenta uma proposta de tipologia das principais áreas de pesquisa neste subdomínio:

«I think the current state of research and fidings can be summarized in terms of the relations between five categories: a) 'objective' environments that is: experts' descriptions of environments; b) subjective cognitive maps of the spatial layout of environments; c) linguistic labels and environmental construct systems, that is: people's urban vocabularies; d) images of the overall character of areas and factors which make space into places; and e) symbolic associations with sape and place and the meaning and significance of the environment in different people's lives. Underlying this tipology is a dimension running from concrete-geometric knowledege of environments (that is, a and b) on the left to abstract-symbolic association with environments (that is $\mathrm{d}$ and $\mathrm{e}$ ) on the rights (p. 63).

É nítida a intersecção destas áreas de estudo com a problemática dominante em psicologia arquitectural, e não é por acaso que se retém a obra de Lynch (1961) como a pedra de fundação das linhas de investigação acima indicadas.

d) A psicologia ambiental personológica. Pelo que acima se disse acerca das raízes históricas da psicologia ambiental, não é de espantar que a este domínio tenham sido alheios $a b$ initio, os contributos dos teóricos da personalidade e dos psicólogos clínicos, mais centrados, tradicionalmente, sobre as problemáticas individuais e sobre a modificação terapêutica dos comportamentos individuais. A própria noção gestáltica de campo de grupo ou campo social levaria a que as atenções se desviassem desses elementos singulares que são os indivíduos para se centrarem no todo que são os grupos, as instituições, os sistemas colectivos. O paradigma personológico nunca foi portanto dominante na psicologia social, e o mesmo se passou com a psicologia ambiental nascente, filha pródiga da psicologia social clássica.

Necessidades de ordem prática levaram todavia os investigadores a debruçarem-se sobre a variação interindividual das respostas aos ambientes, e o paradigma personológico ocupa hoje um lugar não desprezível no conjunto das pesquisas da psicologia ambiental, tentando uma feliz conjugação dos interesses tradicionais dos 
psicólogos sociais e dos interesses tradicionais dos psicólogos clínicos.

Os eco-psicólogos de orientação personológica desenvolveram novos instrumentos de análise orientados para a pesquisa da interface entre as personalidades individuais e as respostas aos ambientes, e dispomos neste momento de questionários especificamente projectados, como o Environmental Response Inventory de Mc Kechnie (1974), o Environmental Preference Questionnaire de Kaplan (1977) e o Environmental Personality Inventory de Sonnenfeld (1969). Escalas mais particulares, como as sensation-seeking scales de Mehrabian e Russell (1974) e Zuckerman, Kolin, Price e Zoob (1964), ou as escalas compostas de prognóstico do comportamento de Arbuthnot (1977) foram igualmente encorajadas e largamente aplicadas nos últimos anos pelos psicólogos ambientais. Broadbent e Gregory desenvolveram um questionário de incomodidade aplicado por Anderson (1971) num estudo sobre as atitudes perante os ruídos, e Soczka $(1980 \mathrm{~b})$ procedeu a um estudo da multidimensionalidade desse questionário, isolando três factores assimiláveis a quadros clínicos da personalidade compativeis com uma leitura freudiana e eto-psiquiátrica. Wapner, Cohen e Kaplan (1976) publicaram um volume onde é clara a influência dominante do paradigma personológico, e onde são de realçar os contributos de Craik («The personality research paradigm in environmental psychology») e de Little («Specialization and the varieties of environmental experience: empirical studies within the personality paradigm»), e em 1977 , a revista Environment and Behavior entregou ao cuidado de dois professores de psicologia ambiental da Uni. versidade de Berkeley, Craik e McKechnie, a organização de um número especial dedicado às relações entre a personalidade e o ambiente (Environment and Behavior, vol. 9, n. ${ }^{\circ}$, 1977).

\section{A PSICOLOGIA AMBIENTAL EM PORTUGAL}

O mínimo que se poderia dizer em relação a este assunto, é que a psicologia ambiental não existe em Portugal. Ou melhor: começa agora a nascer, mercê da iniciativa conjunta do Laboratório Nacional de Engenharia Civil e da Comissão Nacional do Ambiente. O tema de arranque é o estudo do impacte subjectivo de poluição sonora em meios urbanos, com incidência particular na que deriva dos tráfegos rodoviário e aéreo. Um estudo piloto efectuado em 1977 na área de servidão acústica do aeroporto de Pedras Rubras, abordou o problema da incomodidade provocada nos residentes pelo sobrevoo de aviões, e foi demonstrada a necessidade de abrir o estudo à participação da psicologia, dada a componente eminentemente subjectiva dos conceitos de «incomodidade» e «bem estar» ambientais. No estudo paralelo realizado em Julho de 1979 sobre a poluição na cidade de Faro, e ainda centrado sobre a problemática do ruído de tráfego aéreo, incluíram-se já instrumentos psicológicos de análise do problema, e em 1980 abordar-se-á finalmente a cidade de Lisboa.

Tais iniciativas são no entanto extremamente limitadas em relação às necessidades. Em países mais desenvolvidos que o nosso, chegou - se rapidamente à conclusão de que era preciso alargar à participação das populaçôes o planeamento ambiental, e é significativo que um dos primeiros artigos neste domínio se tenha intitulado «Ecologia: vamos ouvir o povo» (Maloney e Ward, 1973). Também em 1973, numa sugestiva comunicação à Conferência de Lund sobre psicologia arquitectural (Kuller, 1973), Donald Appleyard afirmava: «In a few years we have moved from professional dominance of decision-making, through professional concepts of advocacy planning (where professionals represent deprived groups), to the point where people of all classes want the power of environmental decision-making for themselves. Citizens are likely to dispense with old listener roles and claim full participation in environmental decisions. Professionals may have to become more adept at the roles of facilitator, broker, servant and technician, while their traditional roles of leader, artist, and educator are revised.»

Certamente, não é ainda essa situação entre nós, onde, apesar da energia dos movimentos 
sociais dos últimos anos, as populações ainda estão condicionadas pela passividade tradicional que dirigentes políticos de outrora elegeram como «virtude típica» dos portugueses. Mas não é menos certo que é direito fundamental de todos nós (e das gerações que nos seguirão) uma vida harmónica em relação ao ambiente físico, e todos os cidadãos têm algo a dizer sobre as suas aspirações em relação aos seus quadros de vida, sobre o perfil ambiental que desejam. A percepção dos técnicos em relação aos ambientais, por cientificamente esclarecida que pretenda ser, será sempre incompleta se não se souber quais são as percepções das populações, os seus desejos, as suas frustrações e condicionamentos ambientais do bem-estar subjectixo. $\hat{E}$ essencial que se saiba, num mundo onde as cidades não cessam de se agigantar, que homem urbano se está a produzir, que consequências psicológicas advirão do crescente anonimato citadino, das crescentes promiscuidades e densidades populacionais. Só em posse dessas informações é possível um planeamento mais consciente e não autocrático.

Uma das contribuições específicas da psicologia ambiental para o planeamento, está no estabelecimento de índices de qualidade ambiental percepcionada (IQAP), propostos por Craik (1977). Efectivamente, as diversas comissões nacionais para a qualidade ambiental que por todos os países têm sido constituídas estão sobretudo concentradas na luta contra o aumento da poluição e de outras formas de degradação do ambiente, como os abates de florestas, por exemplo. Em relação às normas legislativas que são promulgadas em defesa do ambiente, a tónica é sobretudo posta nos limites que não devem ser excedidos com vista à protecção da saúde pública, quase sempre no sentido mais organicista da expressão. Assim, determinam-se os índices de qualidade física do ar ou da água, através de fórmulas matemáticas de complexidade variável mas que têm em conta o peso relativo de vários indicadores singulares (por exemplo as concentrações de monóxido de carbono, de oxidantes fotoquímicos, de anidrido sulfuroso, etc.), ou de índices compostos de ruído (NNI, NPS, ICR, etc.). Mas é evidente que a saúde não é apenas a ausência de doença ou mal-estar. O planeamento ambiental não é a luta contra o lixo - as comissões do ambiente não são meros substitutos dos serviços de higiene das câmaras municipais. Um conceito integrado de saúde pública, estreitamente ligado à harmonia física e psicológica com o ambiente, passa pela definição das condições subjectivas do bem-estar, e essa pode e deve ser uma das tarefas fundamentais da psicologia ambiental. Aos índices físicos de qualidade ambiental devem urgentemente juntar-se os índices psicológicos da qualidade do ambiente, determinados a partir quer da percepção do ambiente nos sujeitos, quer a partir da permanente comparação entre o ambiente percepcionado e o ambiente desejado. Porque o que está no meio são a frustração e o mal-estar, tantas vezes iludidos através das panaceias sociais que boicotam a reacção enérgica contra os desmandos ecológicos quotidianos a que estamos submetidos: é o passeio dos turistas, ao fim-de-semana, a contrapor-se a uma cidade de betão, sem harmonia, sem regra, sem espaços verdes; é a ilusão de uns dias de férias num recanto aprazível longe de um bulício urbano que é tomado à partida como uma fatalidade só evitável através da fuga. Em muitos destes domínios, é tarefa dos psicólogos intervirem como cidadãos e como técnicos em ordem não só à protecção de um ambiente degradado, mas também e sobretudo para a construção de um ambiente humanamente desejável.

\section{SUMMARY}

The author presents in this paper the social conditions for the upcoming of environmental psychology in the last 15 years, relating the emergence of the new field with the general ecological crisis that affects mainly the industrialized countries. The author analyzes next the historical genesis of the ecological attitude in psychology, namely the extension of Kurt Lewin's field theory and the gestalt concept. The gestalt movement is shortly described and its theoretical principles are reviewed and compared to those of watsonian behaviorism. The epistemological roots of Lewin's theory are put 
forth and the impact of Brunswick's criticism of Lewin on the work of Wright and Barker is also presented. In the last part of the paper, the author expounds the main research trends of contemporary environmental psychology, and the most representative authors of each trend are refered.

\section{REFERENCIAS}

ACH, N. (1910) $\longrightarrow$ Uber den Willensakt und des Temperament: Ein experimentelle Untersuchung, Quelle \& Meyer, Leipzig.

ALTMAN, I. (1975) - Environment and Social Behavior: privacy, personal space, territory and crowding, Brooks Cole, Monterey.

ALTMAN, I. (1976) - «Environmental psychology and social psychology», Personality and Social Psychology Bulletin, vol. 2, 2:96-113.

APPLEYARD, D. (1973) - «Professional priorities for environmental psychologym, in R. Küller (ed.) Architectural Psychology, Proceedings of the Lund Conference, Dowden, Hutchinson \& Ross, Strausbourg.

BACHELARD, G. (1970)-La Formation de l'esprit scientifique, Urin, Paris.

BARKER, R. (1963) - «On the nature of environment», Journal of Social Issues, 19(4):17-38.

BARKER, R. (1965) - «Explorations on ecological psychology», American Psychologist, 20, 1:1-14.

BARKER, R. (1968) - Ecological Psychology, Stanford University Press, Califórnia.

BARKER, R., T. DEMBO e K. LEWIN (1941)«Frustration and regression: a study of young children», University of Iowa. Studies in Child Welfare $, 18,1$.

BARKER, R. e WRIGHT, H. F. (1955)-Midwest and its children, Harper \& Row, N.Y.

BELL, G., E. RANDAL e J. ROEDER (1973)Urban environment and human behavior, Dowden, Hutchinson \& Ross, Strausbourg.

BELL, P., J. FISHER e R. LOOMIS (1978) - Environmental Psychology, Saunders, London.

BRUNSWICK, E. (1939) - «The conceptual focus of some psychological systems», Journal of Unified Science, 8:36-49.

BRUNSWICK, E. (1943) - «Organismic achievement and environmental probability», Psychological $R e-$ view, 50:255-272.

BRUNSWICK, E. (1955) - «In defense of probabilistic functionalism», Psychological Review, 62: 236-242.

BUYTENDIJK, J. (1952) - Traité de Psychologie Animale, P.U.F., Paris.

BUYTENDIJK, J. (1958)-O Homem e o Animal, L.B.L., Lisboa.

CANTER, D. (1969)-Architectural psychology, RIBA Publ. Ltd, London.

CANTER, D. e LEE, T. (1974) - Psychology and the built environment, Architectural Press, London.

CARTWRIGHT, D. (1959) — «Lewinian theory as a contemporary systematic framework», in $\mathrm{S}$. Koch (ed.) Psychology: a study of a science, vol. 2, McGraw-Hill, N.Y.

CARTWRIGHT, D, e FESTINGER, L. (1943) - «A quantitative theory of decision», Psychological Review, 50:595-621.
CHAPLIN, J. E KRAWIEC, T.S. (1974)-Systems and Theories of Psychology, Holt, Rinehart \& Winston, N.Y.

COMISSÃO NACIONAL DO AMBIENTE (1980)Fighting noise in Portugal, M.H.O.P., Secretaria de Estado do Ordenamento Físico, Recursos Hídricos e Ambiente.

CORNATON, M. (1979) - Grupos e Sociedades, Ed. Vega, Lisboa.

CRAIK, K.H. (1973) - «Environmental Psychology», in P. Mussen e M. Rosenzweig (eds.) Annual Review of Psychology, vol. 24.

EIBL-EIBESFELDT, I. (1970) - Ethologie, N.E.B., Paris.

FAUCHEUX, C. (1969) - «Introdução a K. Lewin», Psychologie dynamique, P.U.F., Paris.

FOUCAULT, M. (1963)-Naissance de la clinique, Gallimard, Paris.

GRASSÉ, P.-P. (1951) - Structure et physiologie des sociétés animales, C.N.R.S., Paris.

HALL, K. (1966) - The Hidden Dimension, Doubleday, N.Y.

HARTMAN, G.W. (1935)-Gestalt Psychology, Ronald Press, N.Y.

HEIMSTRA, A. e McFARLING, J. (1974) - Psicologia Ambiental, E.P.U., São Paulo.

HINDE, R. (1970) - Animal Behavior, McGraw-Hill, London.

HOLLOWAY, A. (1974)-Primate aggression, territoriality and xenophobia, Academic Press, N.Y.

HONIKMAN, B. (1971)-Proceedings of the Architectural Psychology. Conference at Kingston, RIBA Publ. Ltd., London.

HOWARD, H.E. (1920)-Territory in Bird Life, Murray, London.

HUTT, J. e HUTT, C. (1970)-Observação directa $\boldsymbol{e}$ medida do comportamento, E.P.U., São Paulo.

ITTELSON, W.H.; PROSHANSKY, H.; RIVLIN, C e WINKEL, G. (1974)-Introduction to Environmental Psychology, Holt, Rinehart \& Winston, New York.

KLOPFER, P. (1968)-Habitats et territories des animaux, Villars, Paris.

KÖHLER, W. (1929) - Gestalt psychology, Liveright, N.Y. [trad. franc. coll. «Idées», Gallimard, Paris]

KOFFKA, K. (1935) - Principles of Gestalt Psychology, Hascourt Brace, N.Y.

KÚLLER, R. (1973)-Architectural Psychology, Dowden, Hutchinson \& Ross, Inc., Strausbourg.

LAGACHE, D. (1949) —L'Unité de la Psychologie, P.U.F., Paris

LENOBLE, R. (1966) - «As origens do pensamento científico moderno», in M. Daumas (Ed.), As Ciências, Arć́dia, Lisboa.

LEWIN, K. (1931) - «The conflict between Aristotelian and Galileian modes of thought in contemporary psychologyn, Journal of Gen. Psychology, 5:141-177.

LEWIN, K. ((1935) - A dynamic theory of persona lity, McGraw-Hill, N.Y.

LEWIN, K. (1936) - Principles of topological psychology, McGraw-Hill, N.Y.

LEWIN, K. (1938) - The conceptual representation and measurement of psychological forces, Duke University, Durham.

LEWIN, K. (1943) - «Forces behind food habits and methods of change», Bull, of the Nat. Research Council, 108:35-65.

LEWIN, K, (1947)-《Frontiers on Group Dynamics», Human Relations, I, 1:2-38. 
LEWIN, K. (1951)-Field theory in Social Science, Harper \& Row, N.Y.

LEWIN, K.; DEMBO, T.; FESTINGER, L. e SEARS, P.S. (1944) - «Level of aspiration», in Hunt (ed.) Personatity and Behavior Disorders, Ronald, N.Y.

LORENZ, K. (1958) - «Methods of approach to the problems of behaviours, The Harvey Lectures, Academic Press, N.Y.

LORENZ, K. (1969)-A Agressäo, Livraria Moracs, Lisboa.

LYNCH, K. (1961) - The image of the city, M.I.T., Cambridge, Mass.

MALONEY, M.P. e WARD, M.P. (1973) - «Ecology: let's hear from the people - an objective scale for the measurement of ecological attitudes and knowledge», American Psychologist, 28, 7:583-586.

MARX, M.H. e HILLIX, W. (1974)-Systems and theories in Psychology, McGraw-Hill, N.Y.

MARTINS DA SILVA, P. (1975)-Ruido de Tráfego Rodoviário, Informação técnica n. ${ }^{\circ} 7$, L.N. E.C., Lisboa.

MARTINS DA SILVA, P. e CORREIA GAGO, M.A. (1977) - Servidão acústica do Aeroporto de Pedras Rubras - Porto, Relatório do S.E.D., L.N.E.C., Lisboa.

McKECHNIE, G.E. (1974) - Manual for the Envi ronmental Response Inventory, Consulting Psychologist Press, Palo Alto, Califórnia.

MCGREW, W. (1972) - An ethological study of children's behaviour, Academic Press, N.Y.

MEHRABIAN, A. P RUSSELL, J.A. (1974)-An approach to environmenial psychology, M.I.T. Press, Cambridge, Mass.

MOORE, G.T. (1979) - «Knowing about environmental knowing», Environment ad Behavior, II, 1:33-70.

MOORE, G.T. e GOLLEDGE, R.G. (1976)--Environmental knowing: theories, research and methods, Dowden, Hutchinson \& Ross, Strausbourg.

PROSHANSKY, H.; ITTELSON, W. e RIVLIN, L. (1970) - Environmental psychology-man and his physical setting, Holt, Rinehart and Winston, N.Y.

RICOEUR, P. (1965)-De l'interprétation-éssai sur Freud, Seuil, Paris.

SOCZKA, L. (1974) - «Ethologie sociale et sociométrie: étude de la structure d'un groupe de $M$. fascicularis en captivitém, Behaviour, 50:254-269.

SOCZKA, L. (1980a)-Estudo psicológico da incomodidade provocada pelo ruído do tráfego aéreo na vizinhança do Aeroporto de Faro, Relatório do L.N.E.C., Proc. 87/1/6009.

SOCZKA, L. (1980b) - As dimensōes subjectivas da incomodidade: análise factorial do questionário de Broadbent-Gregory, L.N.E.C.

SOMMER, R. (1969) - Personal space: the behavioral basis of design, Prentice Hall, N.Y.

STUDER, R. G. (1969) - «The dynamics of behavior-contingent physical systems», in Proshansky et al. (eds.), 1970.

TAVARES DA SILVA, M. (1977) - «Problemas didácticos da introdução à dinâmica de grupo», Análise Psicológica, 1, 1:23.

VALENTE PEREIRA, M. L. (1970)-Inquérito à $\overrightarrow{h a}$ bitação urbana, SED, L.N.E.C., Lisboa.

WATSON, J. B. (1914) - Behavior, Holt, N.Y.

WATSON, J. B. (1919) - Psychology from the standpoint of a behaviorist, Lippincott, Filadélfia.

WATSON, J. B. (1925)-Behaviorism, Norton, N.Y.
Novidades:

\section{Psicologia Ambiental}

Heimstra/McFarling

\section{Enciclopédia da Ecologia}

Vários

Distribuidores das editoras brasileiras:

Editora Pedagógica e Universitária, Lda.

Editora Vozes, Lda.

Enviamos catálogos sobre:

Psicologia

Pedagogia

Filosofia

Antropologia

\section{CONSULTE-NOS}

Na Feira do Livro: Pavilhão N. 68

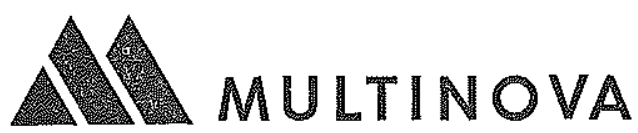

Avenida Santa Joana Princesa, 12-E Telef. 883365 1700 Lisboa 